\title{
A Critical Review on Advances in the Multicomponent Synthesis of Pyrroles
}

\author{
IQBAL AZAD ${ }^{1}$, FIROJ HASSAN ${ }^{1}$, MOHAMMAD SAQUIB ${ }^{2}$, NASEEM AHMAD ${ }^{1}$, \\ ABDUL RAHMAN KHAN ${ }^{1}$, ABDILLAH G. AL-SEHEMI ${ }^{3}$ and MALIK NASIBULLAH ${ }^{1 *}$
}

\author{
'Department of Chemistry, Integral University, Lucknow-226026, India. \\ ${ }^{2}$ Department of Chemistry, University of Allahabad, Allahabad-211002, India. \\ ${ }^{3}$ Department of Chemistry, Faculty of Science, King Khalid University P.O. Box 9004, \\ Abha 61413, Saudi Arabia. \\ *Correponding auhtor E-mail: malik7860@gmail.com, malik@iul.ac.in
}

http://dx.doi.org/10.13005/ojc/340401

(Received: April 07, 2018; Accepted: June 27, 2018)

\begin{abstract}
Nitrogen containing heterocyclic compounds are biologically significant molecules. This is especially true for pyrrole a five membered nitrogen containing aromatic molecule, which is present as a key structural motif in a large number of drugs and lead molecules. This review aims to provide an overview of the multi-component reaction (MCR) based methodologies used for the synthesis of pyrrole and its derivatives, focusing particularly on eco-friendly methods that avoid the use of hazardous reagents, solvents and catalysts are deemed especially relevant to the disciplines of medicinal chemistry and drug discovery.
\end{abstract}

\section{INTRODUCTION}

Heterocyclic molecules are a valuable class of organic compounds which show a broad spectrum of application in medicinal chemistry, ${ }^{1}$ biochemistry, ${ }^{2}$ photochemistry, ${ }^{3}$ material science ${ }^{4}$ and environmental science. ${ }^{5}$ With the increasing emphasis on eco-friendly chemical synthesis in recent decades, new breakthroughs are needed in the synthesis of heterocyclic compounds so as to avoid the use of hazardous chemicals, catalyst, solvent and techniques. In this context the concept of green chemistry ${ }^{6}$ that encompasses a series of consideration like energy consumption, ${ }^{7}$ atom efficiency, ${ }^{8}$ atom economy, ${ }^{9}$ solvent, catalyst and sustainability of the chemical process ${ }^{10}$ has become very relevant. Solvents play a very significant role, in organic synthesis. In addition to their use a reaction media, they are; used in extraction, washing, and separation of the final product. No surprise that volatile organic compounds based solvent is responsible for the major share of the pollution originating from the chemical industry. Consequently, in the past two decades scientists have devoted 
immense efforts towards the replacement of petroleum based hazardous solvents by green solvents. Biodegradable glycerol, ${ }^{11}$ polyethylene glycol (PEG), ${ }^{12}$ ionic liquids (ILs), ${ }^{13}$ water ${ }^{14}$ etc. have been explored extensively as alternative solvents.

Pyrrole and derivatives constitutes one of the most important class of nitrogen containing heterocyclic compounds. ${ }^{15}$ Pyrrole is a key structural motif in a plethora of natural products such as porphyrins, bacteriochlorins, ${ }^{16}$ porphyrinogens ${ }^{17}$ chlorophyll, vitamin B12, bile pigments like bilirubin and biliverdin, and alkaloids isolated from marine sources. ${ }^{18}$ They are an important scaffold in organic synthesis and have immense utility ${ }^{19}$ in, medicinal chemistry ${ }^{20}$ and pharmacology. ${ }^{21}$ Many pyrrole derivatives are also found to possess diverse biological activities such as antibacterial, ${ }^{22}$ antihyperlipidemic, ${ }^{23}$ antioxidant, ${ }^{24}$ antitumor, ${ }^{25}$ antiinflammatory, ${ }^{26}$ antifungal,,${ }^{27}$ antiviral, ${ }^{28}$ anti-HIV, ${ }^{29}$ and analgesic effects. ${ }^{30}$ There most commonly used are many conventional methods for the synthesis of pyrrole derivatives include the Knorr synthesis, ${ }^{31}$ Hantzsh synthesis, ${ }^{32}$ Buchwald-Hartwing coupling, ${ }^{33}$ and Paal-Knorr condensation reaction. ${ }^{34}$ However, multi component reactions (MCRs), ${ }^{35}$ which is a convergent chemical process wherein three or more reactants are combined in such a way that the final product retains significant portions of all the reactants, ${ }^{36}$ have immense advantage over the conventional synthesis in term of flexibility, reduced reaction time, use of less energy, cost effectiveness, variable bond forming efficiency, atom economy, operational simplicity, simple purification of product and eco-friendly nature. ${ }^{37}$ The current emphasis on green chemistry has only increased the relevance of the MCRs approach in organic synthesis. One pot MCR have been successfully employed for the synthesis of a variant pyrrole derivatives. ${ }^{38}$ The main objective of this manuscript is to provide a critical review of the various MCR based syntheses of pyrrole derivatives focusing especially on eco-friendly methods.

\section{The Importance of Pyrrole Compounds}

Pyrrole is an important nitrogen containing heterocyclic compound possessing interesting biological properties. ${ }^{39}$ It is also found in many naturally occurring molecules like pyrroloquinoline quinone $(P Q Q),{ }^{40}$ ryanodine,${ }^{41}$ lamellarin,${ }^{42}$ prodigiosin, ${ }^{43}$ sceptrin ${ }^{44}$ etc.

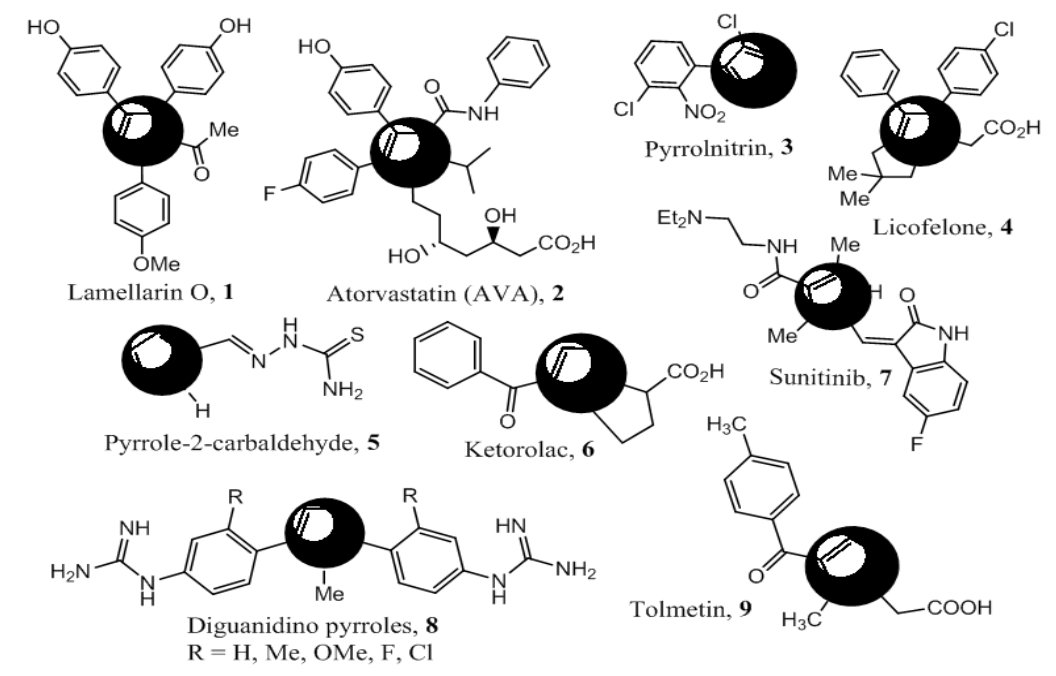

Fig. 1. Some biologically active pyrrole derivatives

Pyrrole is the main heterocyclic moiety in several drugs (Fig. 1) including Lamellarin $O$ (1), a pyrrole alkaloid characterized as a selective inhibitor of breast cancer resistance protein (BCRP). ${ }^{45}$ Atorvastatin (AVA) 2, one of the leading pyrrole drug, is an inhibitor of HMG-CoA reductase
(3-hydroxy-3-methylglutaryl-CoA reductase) and widely used as a lipid lowering agent. It also shows good activity against Plasmodium falciparum and is used in the treatment of cerebral malaria. ${ }^{46}$ It has shown significant neuro-protective and anti-inflammatory activities. Pyrrolnitrin 3 functions 
as a systemic antifungal agent. ${ }^{47}$ Licofelone 4 possesses significant analgesic, anti-inflammatory, and antiasthmatic activities ${ }^{48}$ Pyrrole-2-carbaldehyde 5 is used as antibacterial and HIV-1 integrase inhibitor. ${ }^{49}$ Ketorolac 6 is one of the most important non-steroidal anti-inflammatory drug (NSAIDs). ${ }^{50}$ Sunitinib 7 is a commercially available pyrrole containing drug and is used for the treatment of renal cancer and acts as a multi-targeted receptor tyrosine kinase inhibitor. ${ }^{51}$ Diguanidino-1-methyl2,5-diaryl-1H-pyrrole derivatives 8 have exhibited important antifungal activity against Candida species. ${ }^{52}$ Tolmetin 9 is an important non-steroidal anti-inflammatory drug (NSAID), it works by reducing hormones that cause inflammation as well as pain in the body. ${ }^{53}$

\section{Synthesis of Pyrrole Compounds Using Water as a Solvent}

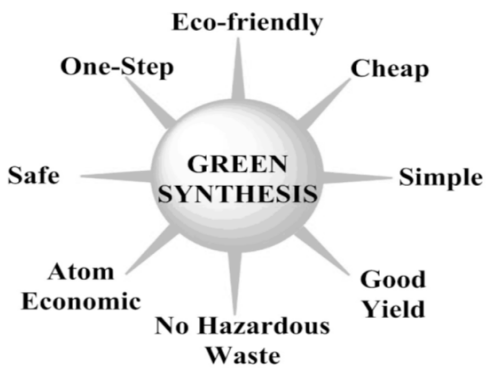

Fig. 2. Green synthesis

One of the main advantages of using water is its ability to form strong hydrogen bonds ${ }^{63-66}$ that gives significant surface tension. One of the most useful conventional methods for the synthesis of pyrrole is the Paal-Knorr cyclization reaction in which a primary amine 11 reacts with 1,4-diketone 12 to furnish the pyrrole derivative 13 (Scheme 1). Recently, $\mathrm{H}$. Veisi et al., reported an eco-friendly
Under near-critical and supercritical conditions water behaves as a pseudo-organic solvent because its dielectric constant decreases substantially toward The organic molecules at room temperature compared to common organic solvents, ${ }^{54}$ The unique physical and chemical properties of water such as high specific heat, surface tension, dielectric constant, large cohesive energy, density and ability to form hydrogen bonds and its amphoteric nature, coupled with its ability to influence the reactivity and selectivity of chemical reactions ${ }^{55}$ have served to make it a solvent of choice in organic synthesis. ${ }^{56}$ Many organic reactions are greatly facilitated when water is employed as the solvent ${ }^{57}$ due to their hydrophobic effects. Finally, the use of water as solvent facilitates unique solution modes and assembly processes, enabling selectivity and reactivity that are often difficult to achieve in organic solvents. ${ }^{58-62}$

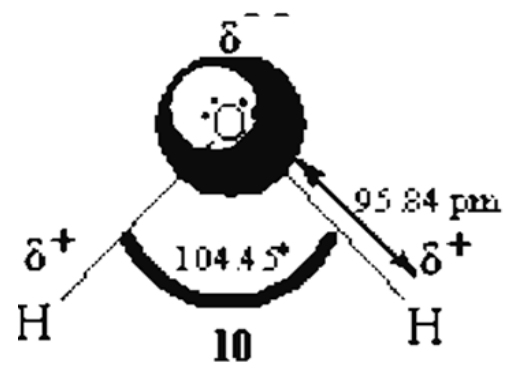

Fig. 3. Chemical structure of water

version of the classical experimental procedure in the year 2013 for the synthesis of $\mathrm{N}$-substituted pyrrole by using sodium dodecyl sulfate (SDS) in water at room temperature. ${ }^{67}$ The reactant formed micelle in water due to their hydrophobic nature and were forced inside the hydrophobic core of the micelle, thus permitting the reaction to take place more easily, leading to the formation of the product in excellent yields.

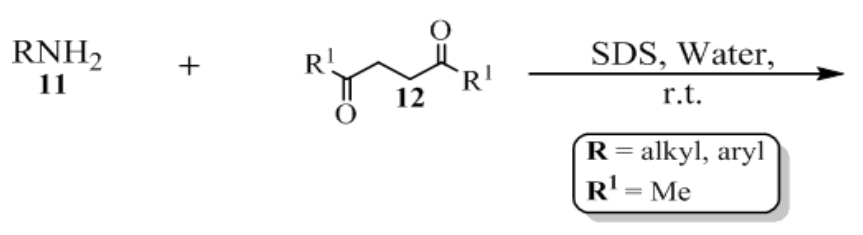

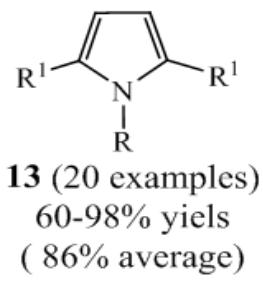

Scheme 1. One pot two component synthesis of $\mathrm{N}$-substituted pyrroles

$\mathrm{Li}$ et al., developed an eco-friendly and cost effective simple protocol for the synthesis of pyrrole derivatives. ${ }^{18} \mathrm{He}$ performed the reaction by using $50 \%$ gluconic acid in aqueous solution (GAAS) at $100^{\circ} \mathrm{C}$ (Scheme 2). ${ }^{68}$ They observed that ionic liquid is the most promising solvent to obtain 
the desired product in high yields. The mechanistic pathway for this reaction involved Michael addition and cyclization by the elimination of nitroxyl and water to provide the substituted pyrrole derivatives 18 (Figure 4).

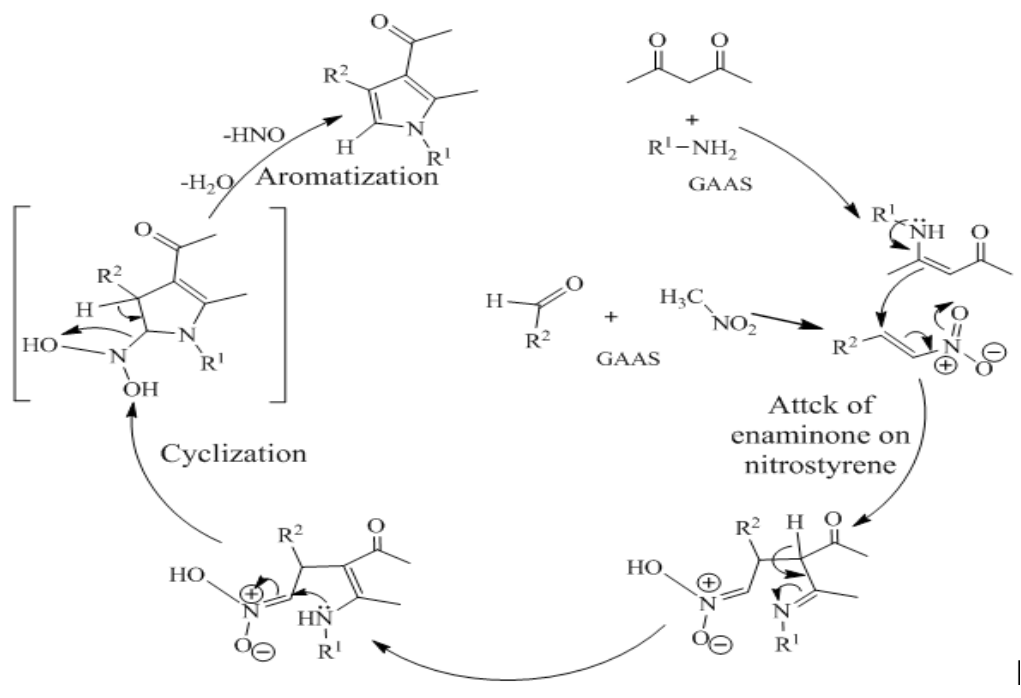

Scheme 2. One pot four component synthesis of substituted pyrrolefrom amine, aldehyde, diketone, and nitroalkane

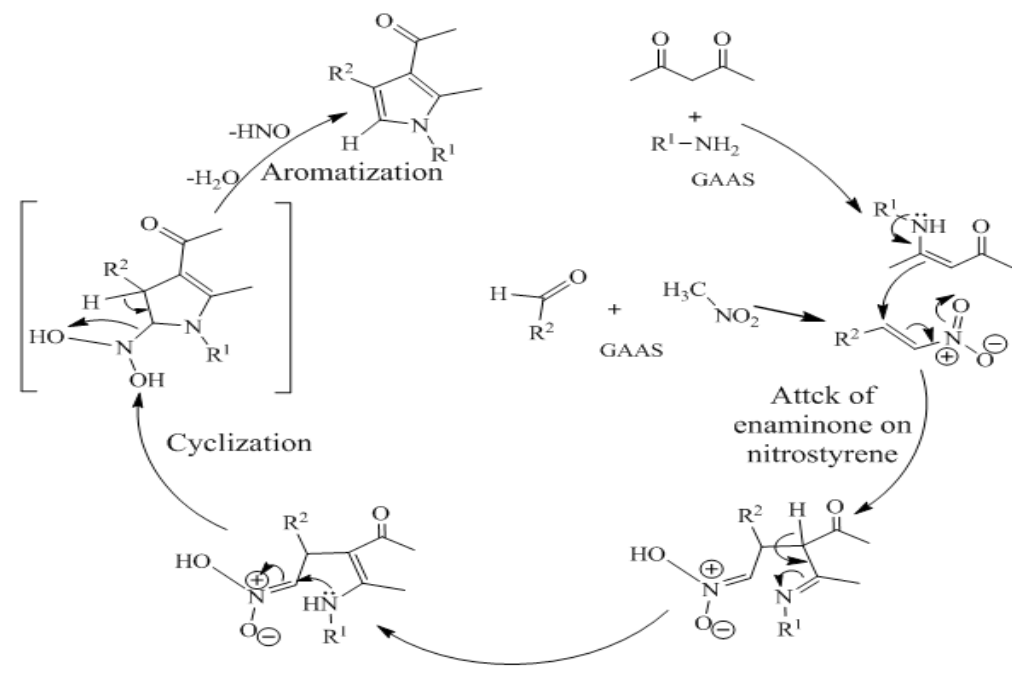

Fig. 4. Proposed mechanistic pathway for the above reaction

An eco-friendly and simple, regio- and stereo-selective protocol for the synthesis of polyfunctionalized pyrrole derivatives 21 , in good yield, was reported by the M. Masoudi and co-workers through a novel one-pot two-component reaction of enamines of $\beta$-ketoesters 19 and $\alpha$-oxoaldehydes 20 in the presence of triphenylphosphine $\left(\mathrm{PPh}_{3}\right)$ (Scheme 3). ${ }^{69}$ On the basis of the regiochemistry of the addition of enaminones to aryl-glyoxals, it is assumed that condensation of the aryl-glyoxal derivative with the enaminone derivative at the aldehydic carbon, first afforded an intermediate, which was subsequently converted into another intermediate, the phosphonium betaine intermediate, by the conjugate addition of the triphenylphosphine. Elimination of triphenylphosphine oxide from this intermediate ultimately led to the polyfunctionalized pyrrole derivatives 21 (Figure 5). 


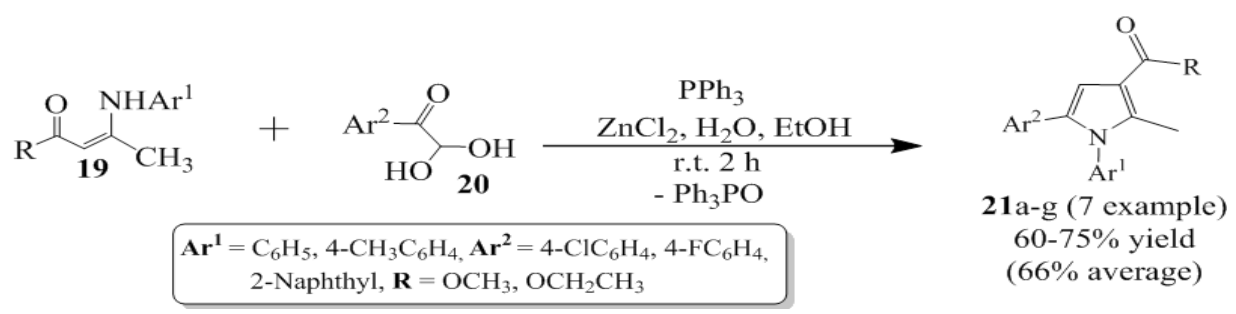

Scheme 3. One pot two component synthesis of poly-functionalized pyrrole derivatives

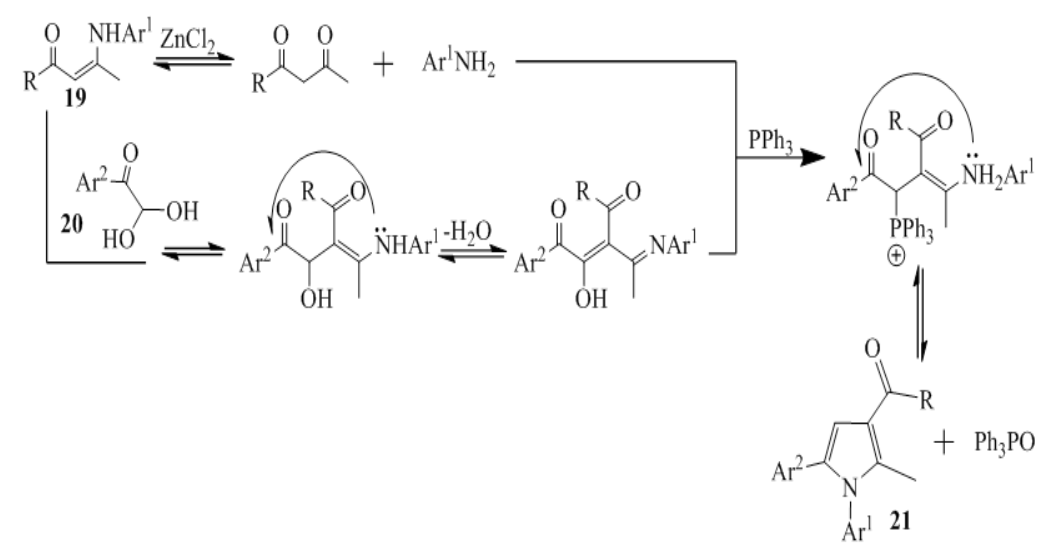

Fig. 5. The proposed mechanism for scheme 3

Reddy et al., in 2015 described an impressive one-pot three component reaction for the synthesis of polysubstituted pyrrole derivatives 25 using nitro compounds 22 , phenacyl bromide or its derivatives 23 and dialkyl acetylene dicarboxylates
(DMAD) 24 (Scheme 4). In this procedure, indium metal powder was used as a catalyst in dilute aqueous hydrochloric acid solution and the reaction was performed at room temperature for $10-16$ hours. $^{70}$

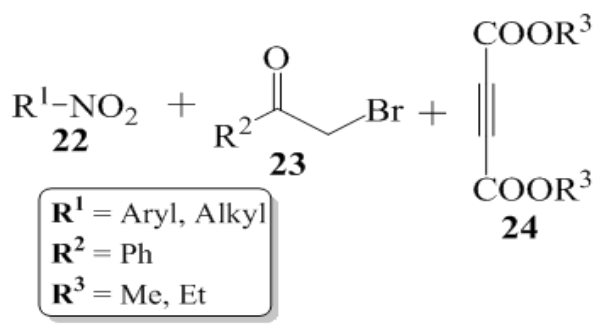


dipyrromethenes 28 using aldehydes 26 and pyrrole 27 in water at room temperature. The mechanism involved Friedel Craft reaction and the final product was obtained with good yields (Scheme 5). ${ }^{74}$

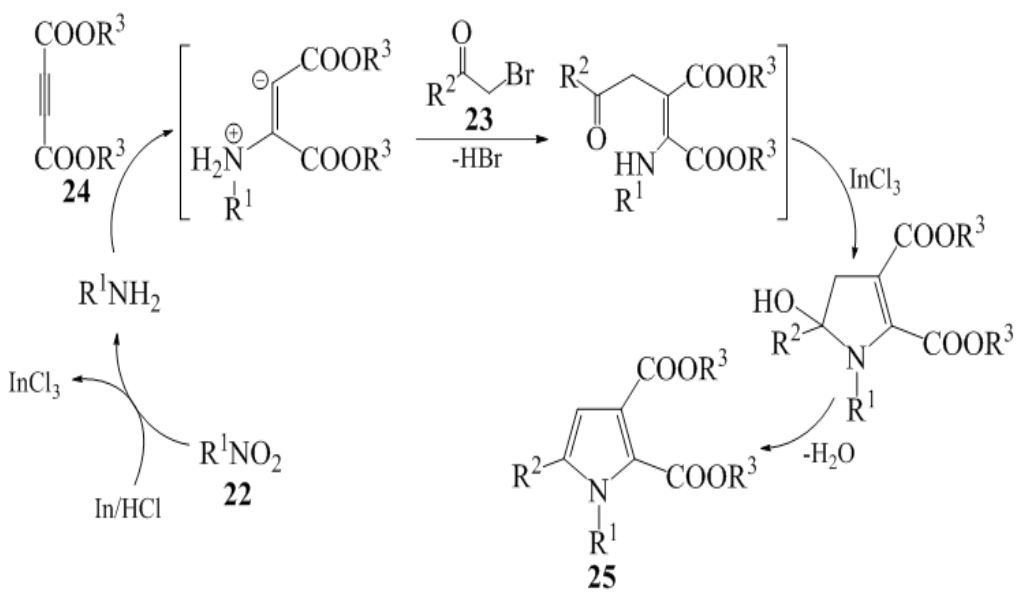

Fig. 6. Mechanistic pathway for scheme 4

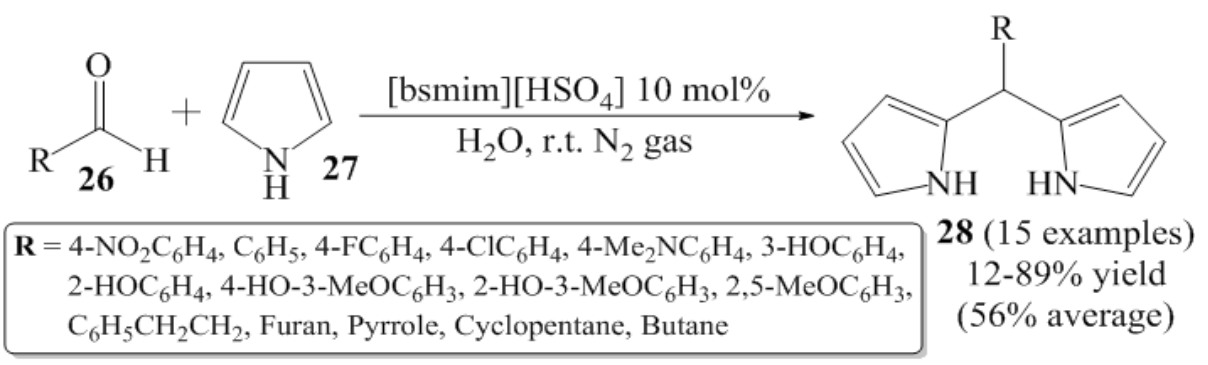

Scheme 5. Synthesis of dipyrromethenes derivatives

Rajaguru et al., in 2017 synthesized tetra-substituted pyrrole derivatives 31 from $\alpha$-azidochalcones 29 with copper $\beta$-diketonates 30 in aqueous micellar medium using cetyltrimethyl ammonium chloride (CTAC) as a surfactant, at $100^{\circ} \mathrm{C}$. in the presence of copper (II) acetylacetonate as a catalyst (Scheme 6). ${ }^{75}$ The mechanistic pathway for the formation of substituted pyrroles 31 is initiated by thermolysis of $\alpha$-azidochalcone 29 which then undergoes denitrogenative decomposition to form a highly strained three membered cyclic imine, $2 \mathrm{H}$-azirine. The solvolysis of metal $\beta$-diketonate 30 followed by the addition of the intermediate results in the aziridine compound, which then undergoes intramolecular nucleophilic addition to the carbonyl group with a nitrogen lone pair to furnish the 2, 5-Dihydro-1H-pyrrole intermediate followed by isomerization to form substituted pyrroles 31 .

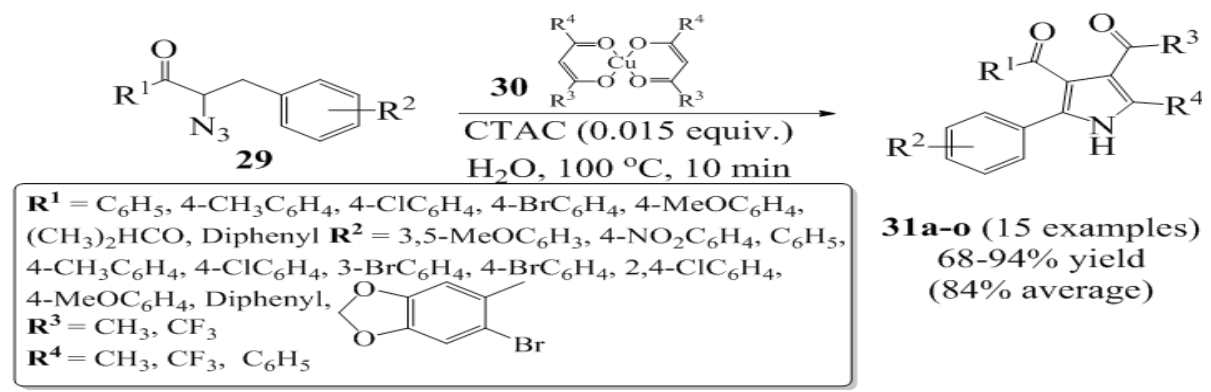


Substituted functional indoloquinoline derivatives were prepared by Shi et al., in good yield, by a one-pot two component method using substituted indole 32 and benzo[c]isoxazole 33 in the presence of $\left[\mathrm{Cp}^{*} \mathrm{RhCl}_{2}\right]_{2}, \mathrm{AgSbF}_{6}$ and $\mathrm{NaOAc}$ at $100^{\circ} \mathrm{C}$, in the presence of water. (Scheme 7$){ }^{76}$<smiles>[R]c1ccc2c(ccn2CP)c1</smiles>

33

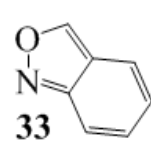

$\mathbf{R}=\mathrm{H}, \mathrm{Me}, \mathrm{MeO}, \mathrm{F}, \mathrm{Cl}, \mathrm{Br}, \mathrm{MeCO}_{2}$

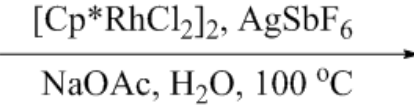

$$
\begin{gathered}
59-94 \% \text { yield } \\
\text { (81\% average) }
\end{gathered}
$$$$
34 \text { ( } 23 \text { examples) }
$$

Scheme 7. Synthesis of substituted functional indoloquinoline derivatives

In recent years, with a growing emphasis on green chemistry, a lot of efforts is being invested towards the development of metal free protocols for the synthesis of biologically important organic moieties. ${ }^{77}$ Farahani et al., recently reported the synthesis of substituted pyrrole derivatives 38 by a three component reaction of primary amine 37 , alkyl propiolate 35 and diethyl oxalate 36 in water at $70^{\circ} \mathrm{C}$ for $3 \mathrm{~h}$ using water as a solvent in catalyst free condition (Scheme 8). ${ }^{78}$

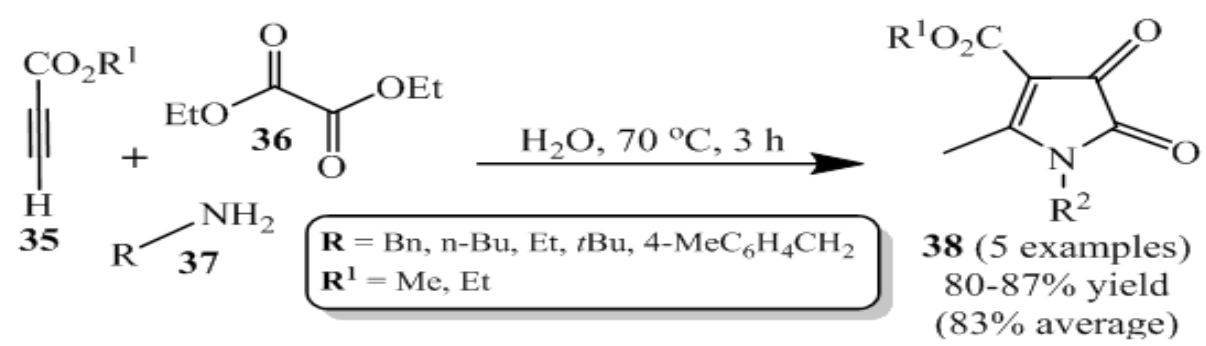

Scheme 8. One pot three component synthesis of polysubstituted pyrrole derivatives

Chen and co-workers for the first time developed a thermodynamically versus kinetically controlled, three component reaction utilizing heterocyclic ketene aminals (HKAs) 39, arylglyoxal monohydrates 40 and cyclohexane-1,3-diones 41 for the synthesis of the highly functionalized bicyclic pyrrole derivatives $42 \mathrm{a}$ and $42 \mathrm{~b}$. in high yield, using a water based green solvent system $\left(\mathrm{H}_{2} \mathrm{O}: \mathrm{EtOH} / 3: 1\right.$ ratio), under catalyst free conditions (Scheme 9). ${ }^{79}$ The mechanism involved dual regioselective pathways as exemplified in Fig. 7 . The HKAs, with a strong electron withdrawing keto-carbonyl group at the $\alpha$-position and an electron-donating gem-diamino group on the di-azaheterocycle, added to the heteroarene component reacting with the tertiary carbon to form the first intermediate through an azaene reaction associated with the formation of a $\mathrm{C}-\mathrm{C}$ bond. This is followed by the tautomerization of the first intermediate to the second intermediate by an imine-enamine process followed by the intermolecular attack of the $\mathrm{NH}$ group to carbonyl group, to afford the third intermediate, which immediately converts into the fourth intermediate by formation of two $\mathrm{C}-\mathrm{C}$ bonds and one $\mathrm{C}-\mathrm{N}$ bonds. Subsequent, aromatization leads to the fifth intermediate which not only rapidly transforms into one of the target molecules $42 \mathrm{a}$, through enolization, but also slowly transforms into its hydroxylated derivatives $42 \mathrm{~b}$, through a tandem the oxidation of the fifth intermediate and the nucleophilic addition of a water molecule to the sixth intermediate.

Ramana et al., established a catalyst free, three component procedure for the synthesis of 4-(1H-indol-3-yl)-3,4-dihydroquinazolin- $2(1 \mathrm{H})$ ones 48 and 4-(2-hydroxynaphthalen-1-yl)-3,4dihydroquinazolin-2(1H)-ones derivatives 46 . In this investigation, they reacted o-formyl carbamate 43 , amine 44, and 2-naphthol 45 or indole derivatives 47 in $\mathrm{H}_{2} \mathrm{O}$ at $130^{\circ} \mathrm{C}$ for $8 \mathrm{~h}$ to obtain the desired product in high yield (Scheme 10)..$^{80}$ 


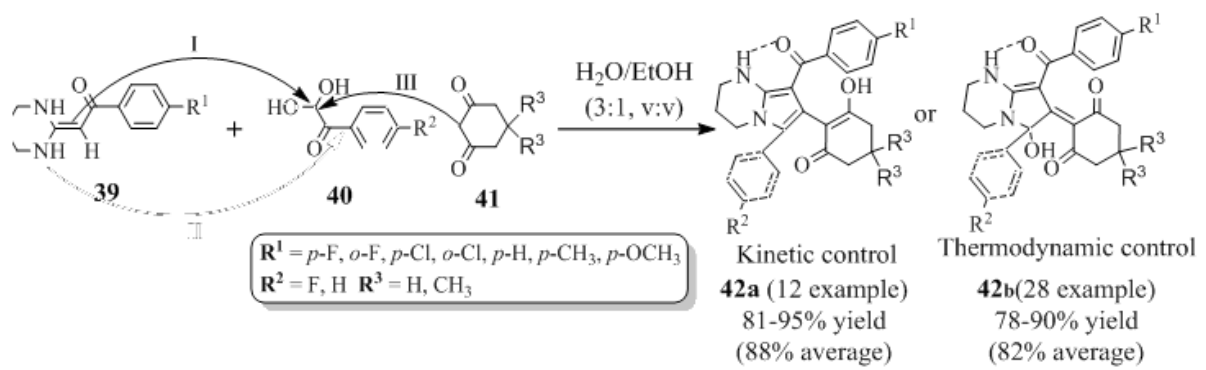

Scheme 9. Synthesis of mono- and bis-N-aryl-3-aminodihydropyrrol-2-one-4-carboxylates

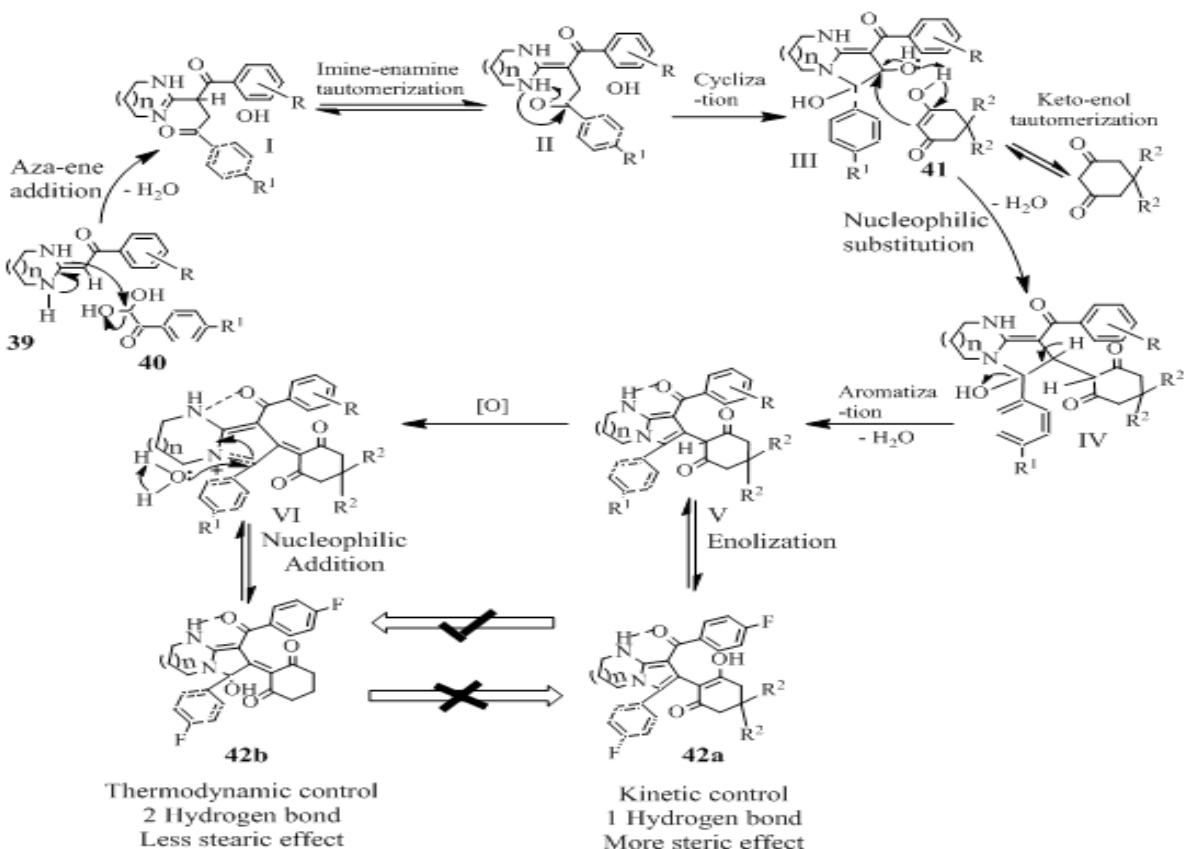

Fig. 7. Proposed mechanism for the scheme 9<smiles>[R1]c1[nH]c2ccccc2c1C1c2ccccc2C([R1])C(=O)N1[R]</smiles>

48 (27 examples) $65-95 \%$ yield (83\% average)

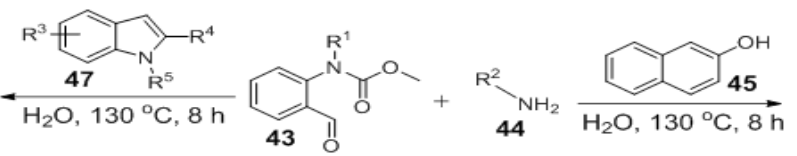

$\mathbf{R}^{1}=\mathrm{H}, \mathrm{CH}_{3}, \mathrm{CH}_{2} \mathrm{CHCH}_{2}, \mathrm{CH}_{2} \mathrm{C}_{6} \mathrm{H}_{5} \mathbf{R}^{2}=\mathrm{CH}_{3}, \mathrm{C}_{4} \mathrm{H}_{9}$,

$\mathrm{CH}\left(\mathrm{CH}_{3}\right), \mathrm{CH}_{2} \mathrm{C}_{6} \mathrm{H}_{5}, \mathrm{CH}_{2} \mathrm{C}_{6} \mathrm{H}_{5} \mathrm{CH}_{3}, \mathrm{CH}_{2} \mathrm{C}_{6} \mathrm{H}_{5} \mathrm{OCH}_{3}$.

$\mathrm{CH}_{2}\left[o \mathrm{Cl}\left(\mathrm{C}_{6} \mathrm{H}_{5}\right)\right], \mathrm{CH}_{2}\left[o \mathrm{Br}\left(\mathrm{C}_{6} \mathrm{H}_{5}\right)\right], \mathrm{CH}_{2}\left[m \mathrm{Br}\left(\mathrm{C}_{6} \mathrm{H}_{5}\right)\right]$. $\mathrm{CH}_{2}\left[p \mathrm{~F}\left(\mathrm{C}_{6} \mathrm{H}_{5}\right)\right], \mathrm{CH}_{2}\left[p \mathrm{OCF}_{3}\left(\mathrm{C}_{6} \mathrm{H}_{5}\right)\right]$, cyl- $\mathrm{C}_{3} \mathrm{H}_{5}$, cyl- $\mathrm{C}_{6} \mathrm{H}_{13}$ $\mathrm{CH}_{2} \mathrm{C}_{4} \mathrm{H}_{3} \mathrm{O}, \mathrm{CH}_{2} \mathrm{C}_{5} \mathrm{H}_{4} \mathrm{~N} \mathrm{R}^{3}=\mathrm{H}, \mathrm{CH}_{3}, \mathrm{OCH}_{3}, \mathrm{Br}, \mathrm{NO}_{2}$ $\mathbf{R}^{4}=\mathrm{H}, \mathrm{CH}_{3} \mathbf{R}^{5}=\mathrm{H}, \mathrm{CH}_{3}$

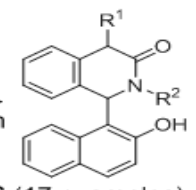

46 (17 examples) $72-89 \%$ yield (82\% average)

$\mathbf{R}^{1}=\mathrm{H}, \mathrm{CH}_{3}, \mathrm{C}_{6} \mathrm{H}_{13}, \mathrm{CH}_{2} \mathrm{CHCH}_{2}$, $\mathrm{CH}_{2} \mathrm{C}_{6} \mathrm{H}_{5} \mathbf{R}^{2}=\mathrm{H}, \mathrm{CH}_{3}, \mathrm{C}_{2} \mathrm{H}_{5}, \mathrm{C}_{4} \mathrm{H}_{9}$ $\mathrm{CH}\left(\mathrm{CH}_{3}\right), \mathrm{CH}_{2} \mathrm{C}_{6} \mathrm{H}_{5}, \mathrm{CH}_{2} \mathrm{C}_{6} \mathrm{H}_{5} \mathrm{CH}_{3}$ $\mathrm{CH}_{2} \mathrm{C}_{6} \mathrm{H}_{5} \mathrm{OCH}_{3}, \mathrm{CH}_{2}\left[\mathrm{OBr}\left(\mathrm{C}_{6} \mathrm{H}_{5}\right)\right]$, $\mathrm{CH}_{2}\left[p \mathrm{~F}\left(\mathrm{C}_{6} \mathrm{H}_{5}\right)\right], \mathrm{CH}_{2} \mathrm{C}_{6} \mathrm{H}_{5}\left(\mathrm{OCH}_{3}\right)_{3}$ cyl- $\mathrm{C}_{3} \mathrm{H}_{5}$, cyl- $\mathrm{C}_{6} \mathrm{H}_{11}$

Scheme 10. One pot three component synthesis of substituted indole and hydro-quinazolin derivatives

\section{Synthesis of Pyrrole Compounds Using lonic Liquid as a Solvent}

In 2014, Anamik Shah and co-workers performed a catalyst free, simple synthesis of penta-substituted pyrrole derivatives 54 or 55 via a one pot five component reaction (Scheme 11), ${ }^{81}$ using 2,2-dimethyl-1,3-dioxane-4,6-dione 49a orpyrimidine2,4,6(1H,3H,5H)-trione 53b, 4-alkylanilines 50, 1-(4fluorophenyl)-2,2-dihydroxyethan-1-ones 51 and dimethyl acetylene dicarboxylates (DMAD) 52. The reaction was carried out in anhydrous ethanol, in 1-4. 


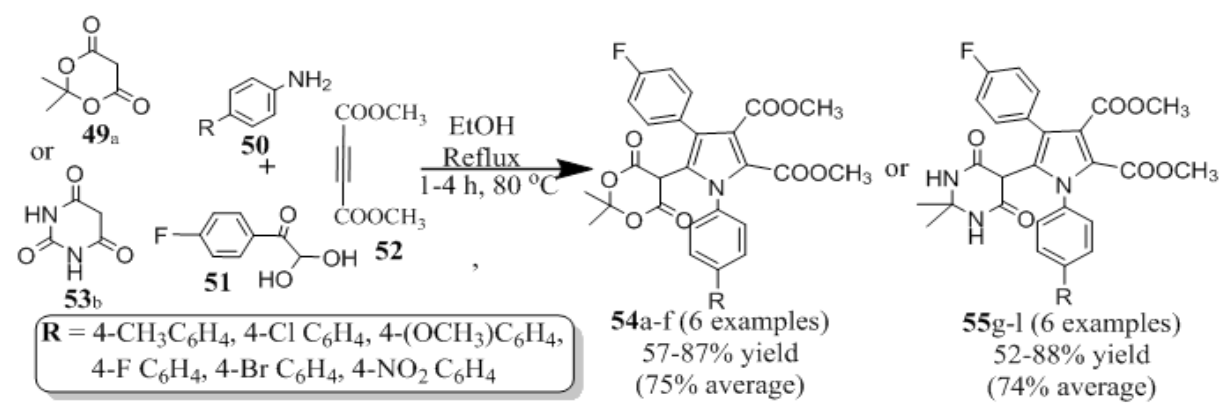

Scheme 11. Four component synthesis of penta-substituted pyrrole under catalyst free conditions

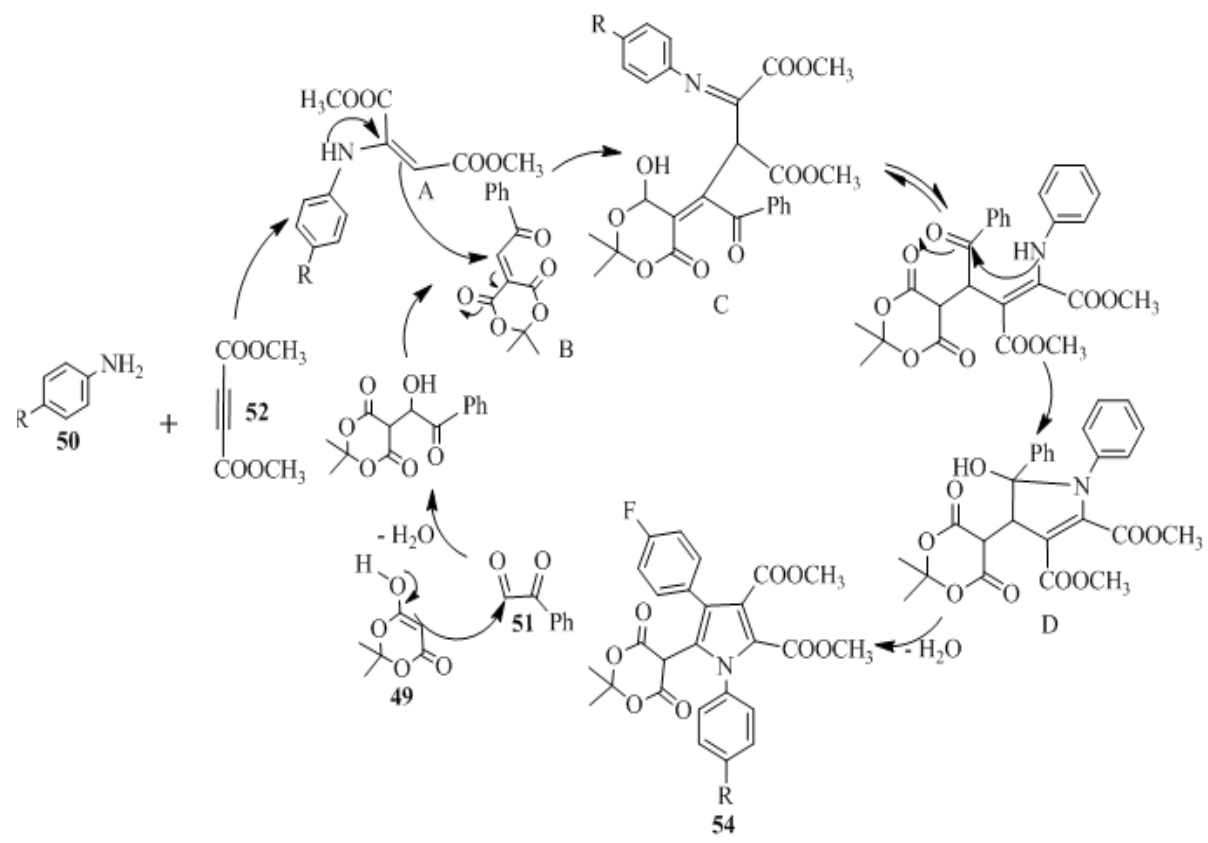

Fig. 8. Proposed mechanism for the formation of the penta-sustituted pyrrole 54 and 55

Wang et al., have developed a highly efficient, catalyst free green method for the one pot four component syntheses of pyrrole derivatives 60. This method presents a new approach for the synthesis of pyrrole derivatives. They observed the possibility of the reaction of 4-hydroxy-2H-chromen2-one 56 with phenyl glyoxal monohydrate 56 , dialkyl but-2-ynedioate 57 and arylamine $58 .{ }^{82}$ The protocol proceeded efficiently with high yield without the need for chromatography or recrystallization. This synthetic methodology demostrates that various substituted pyrrole can be designed and constructed through the regulation of the starting materials of 4-hydroxy$2 \mathrm{H}$-chromen-2-one in Scheme 14. In the first step of the reaction, the addition of alkynoate 59 and amine 58 gave the enamine as the first intermediate.
Knoevenagel condensation of 4-hydroxycoumarin 57 with phenylglyoxal 56 gave the second intermediate. Michael addition of first intermediate and second intermediate yielded the third intermediate, which on intramolecular cyclization and dehydration led to the formation of the desired pyrrole derivatives 60 .

Niknam et al., reported a new multicomponent protocol for the synthesis of substituted pyrroles by first refluxing aromatic aldehyde 61 , in the presence of ionic $3 \mathrm{~mol} \%$ ionic liquid and $30 \mathrm{~mol} \%$, sodium hydroxide, in absolute ethanol in for $30 \mathrm{~min}$. to form benzoin followed by the addition of the 1 , 3-dicarbonyl compound 62 and ammonium acetate 63 (Scheme 13). The reaction mixture was then cooled to room temperature and the precipitate formed was 
filtered and washed with water in order to remove the IL $4 .{ }^{83}$ The resulting solid were recrystallized from ethanol to obtain the pure substituted pyrrole 64 in a metal free, eco-friendly, one pot five component sequential reaction was reported by S. Ambethkar which involved the coupling of acetophenone 65, N,Ndimethylformamide-dimethylacetal 66 , substituted amine 67, arylglyoxal 68 and malononitrile 69 in methanol under reflux for $1.5 \mathrm{~h}$ to obtained novel pyrrole cyano-acetamides 70 in high yields (Scheme14). ${ }^{84}$ The experimental result showed that solvent and temperature played significant role in the reaction productivity.

The mechanistic pathway for the synthesis of substituted pyrrole 70 is shown in
Fig. 10. Initially the intermediate is formed by the formylation reaction between acetophenone 65 and $\mathrm{N}, \mathrm{N}$-dimethylformamaide dimethylacetal 66 , which undergoes Michael addition with amine 67 followed by elimination of dimethylamine to form the second intermediate. Knoevenagel condensation reaction between aryl-glyoxal monohydrate 68 and malononitrile 69 forms the third intermediate. Subsequently the Michael addition of the second intermediate to the third intermediate produces iminium ion giving the fourth intermediate, which undergoes an imine-enamine-tautomerization driven intramolecular cyclization leading to the formation of the furano-pyrrole intermediate which undergoes ring opening to form the target pyrrole 70.

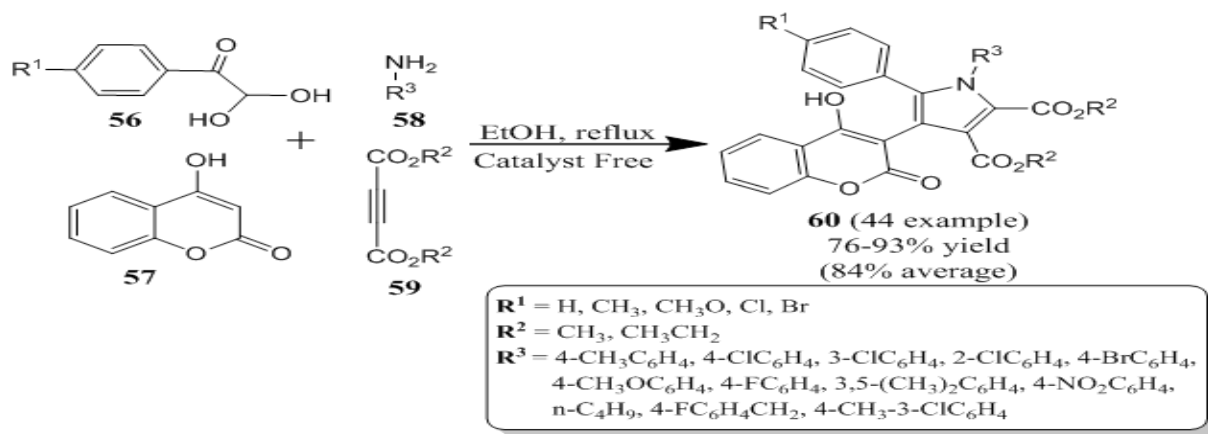

Scheme 12. One-pot four-component synthesis of poly-substituted pyrrole

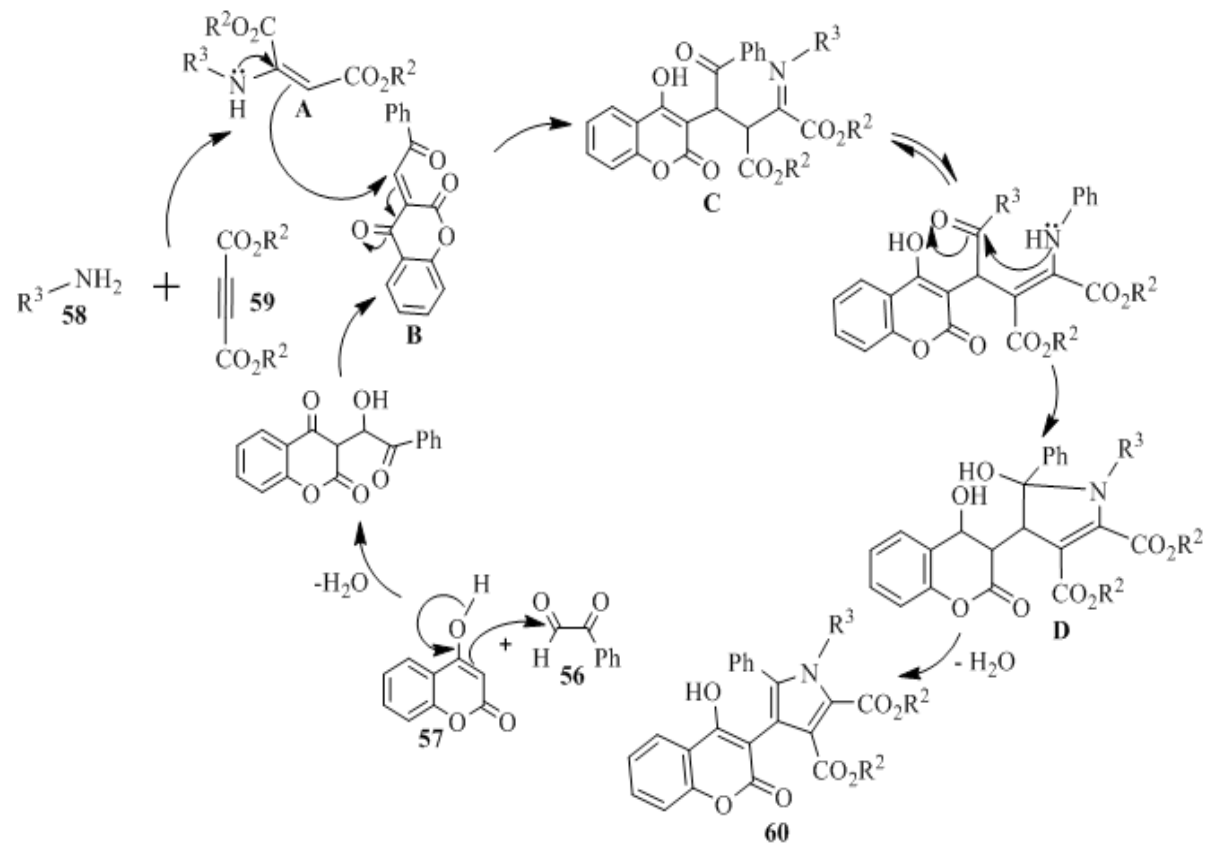

Fig. 9. Probable Mechanism for the formation of the poly-substituted pyrroles 69 

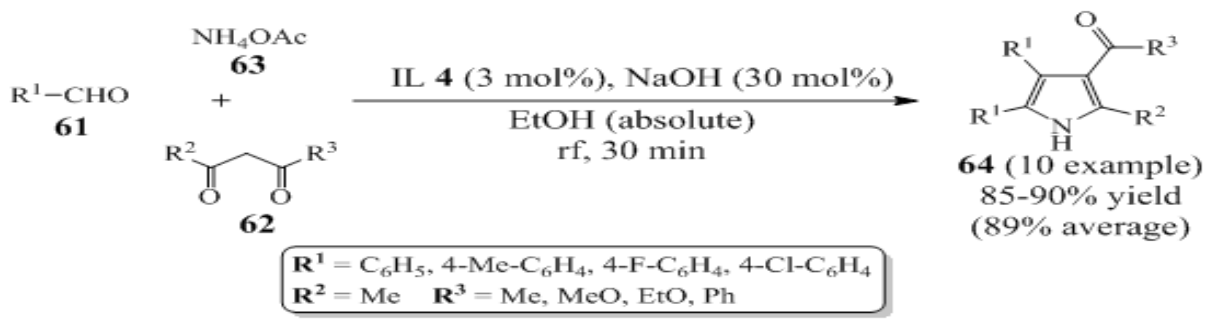

Scheme 13. One-pot three-component synthesis of substituted pyrrole

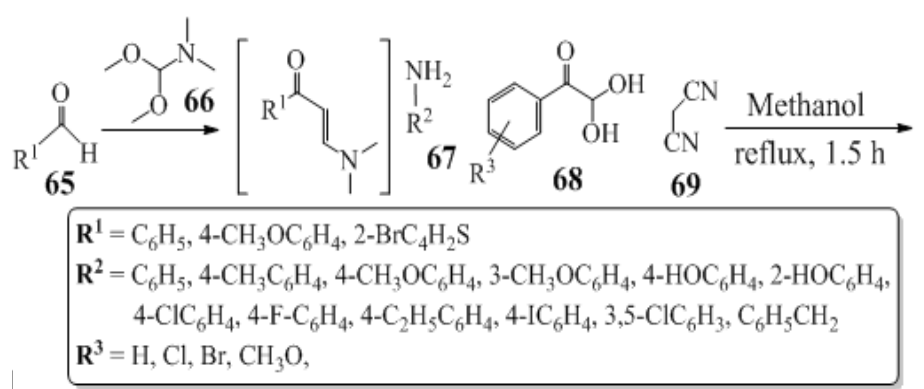

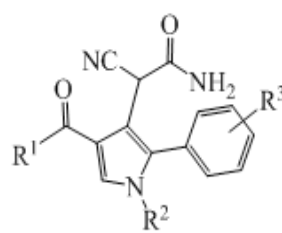

70 ( 21 examples)

$52-83 \%$ yield

( $76 \%$ average)

Scheme 14. One-pot four-component synthesis of poly-substituted pyrrole

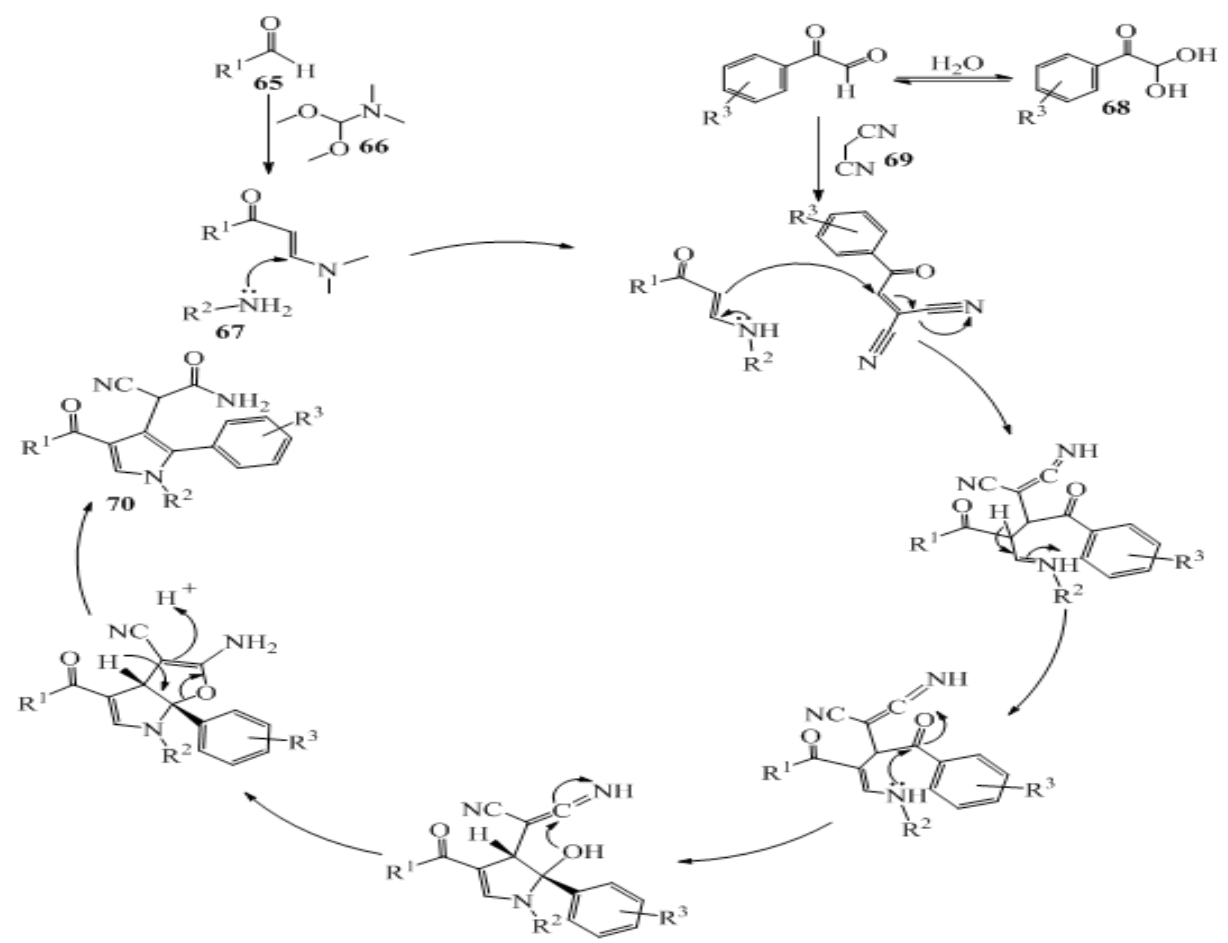

FIG. 10. Probable mechanistic pathway involved scheme 14

Liu and co-worker developed an efficient $\mathrm{FeCl}_{3} \cdot 6 \mathrm{H}_{2} \mathrm{O}$ promoted cascade protocol for the asymmetric synthesis of indole-substituted dihydrocoumarin 74 , in excellent yield via a one-pot three component coupling of $\alpha$-oxoketene dithioacetals 71 , salicylaldehyde 72 and indole 
derivatives 73 (Scheme 15). ${ }^{85}$ They observed that the three-component reaction with excellent yield. This reaction proceeds easily at room temperature through electrophilic substitution followed by hydrolysis.

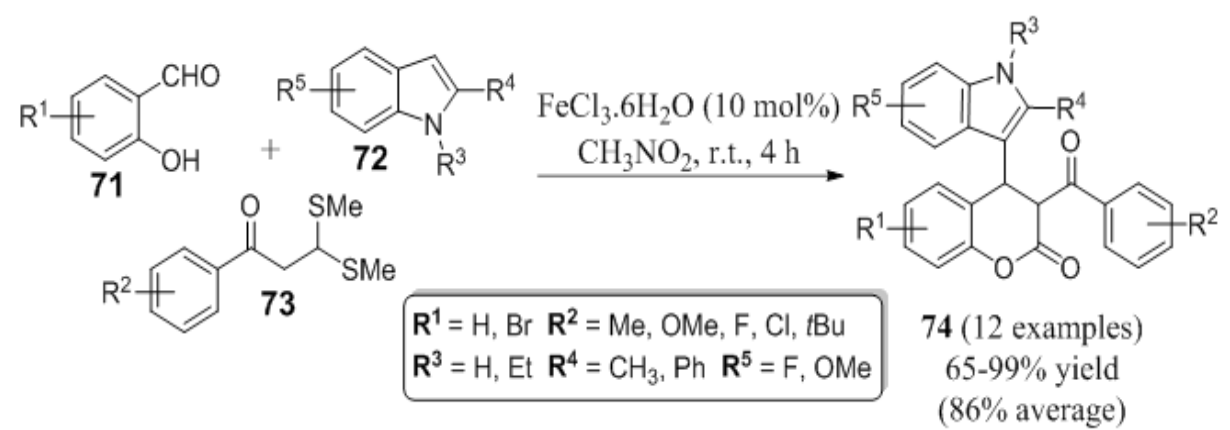

Scheme 15. One pot three component synthesis of indole-substituted dihydrocoumarin

Shi et al., have reported a MCR protocol which involves the reaction of 5-methylindoline-2,3dione 75 , sarcosine 76 and methyl 3-phenylpropiolate 77 in isopropanol at reflux for $8 \mathrm{~h}$ to furnish the desired spiro[indoline-3,2'-pyrrole] derivatives 78 with excellent yield under metal free conditions (Scheme 16). ${ }^{86}$ The proposed mechanism for this reaction envisages condensation of isatin 75 with sarcosine 76 to form the corresponding azomethine ylide as the first intermediate, after which the protic solvent of isopropanol is thought to promote the decarboxylation of the initially formed intermediate to form the 1,3-dipolar second intermediate. The 1,3-dipolar cycloaddition of the second intermediate with methyl 3-phenylpropiolate 77 results in the target product spiro[indoline-5 3,2'-pyrrole] 78.
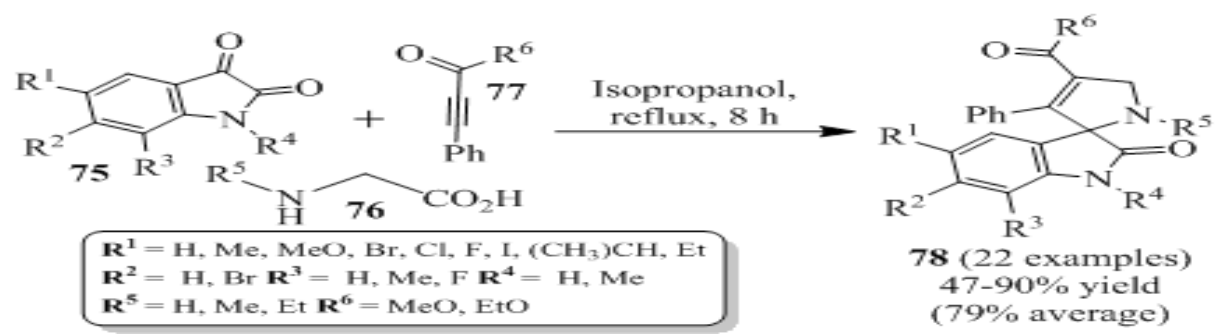

Scheme 16. One pot three component synthesis of spiro[indoline-3,2'-pyrrole] derivatives

Due to the drawbacks associated with the use of metals as catalyst in organic synthesis, many workers have directed their efforts towards the development of synthetic approaches involving the use of recyclable green catalysts.

In 2014 Sajadikhah et al., used $\mathrm{Ph}_{3} \mathrm{CCl}$ (10 mol\%) as an efficient and effective green catalyst for the one-pot, four component synthesis of pyrrole derivatives 83 and 84 at room temperature (Scheme 17). ${ }^{87} \mathrm{~A}$ mixture of amines 80 and 81 , dialkyl acetylene dicarboxylate 79 and aromatic aldehyde 82 were stirred at room temperature in $\mathrm{EtOH}$ in the presence of $\mathrm{Ph}_{3} \mathrm{CCl}$ as a catalyst to obtain the products 83 and 84 by direct filtration.

Initially, amine 80 reacts with the dialkyl acetylene dicarboxylate 79 leading to the formation of intermediate I followed by the condensation between amine 81 and formaldehyde 82 in the presence of triphenylmethyl chloride to produce imine intermediate II. Subsequently, intermediate I undergoes Mannich type reaction with imine intermediate II to deliver a reactive intermediate III, which is immediately converted to intermediate IV by cyclization reaction. Finally, intermediate IV tautomerized to furnish the corresponding mono- or bisdihydro-2-oxopyrrole derivative 83 or 84 . 
Recently, M. Kangani et al., reported a one-pot four-component strategy using lactic acid (20 $\mathrm{mol} \%)$ as a green and recyclable catalyst. They used cheap and easily available starting materials dimethyl and/or diethyl acetylene dicarboxylate
79 , anilines 80 and 81 and formaldehyde 82 under optimized reaction conditions 88 whence poly-substituted pyrrole derivatives 84 were obtained in high yields (Scheme 17). The possible reaction mechanism is suggested in Figure 11.

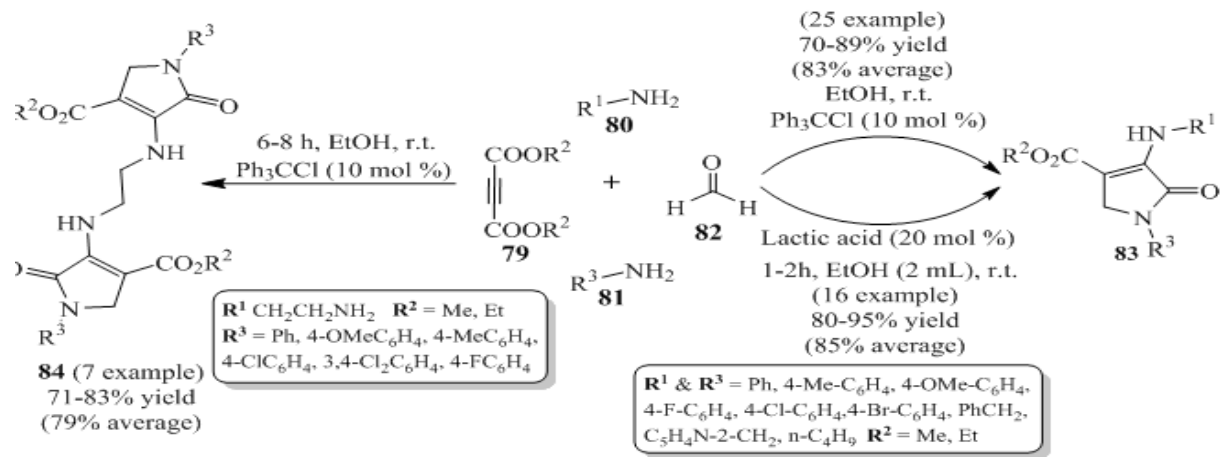

Scheme 17. Triphenyl methyl chloride catalyzed one-pot four component synthesis of substituted pyrroles

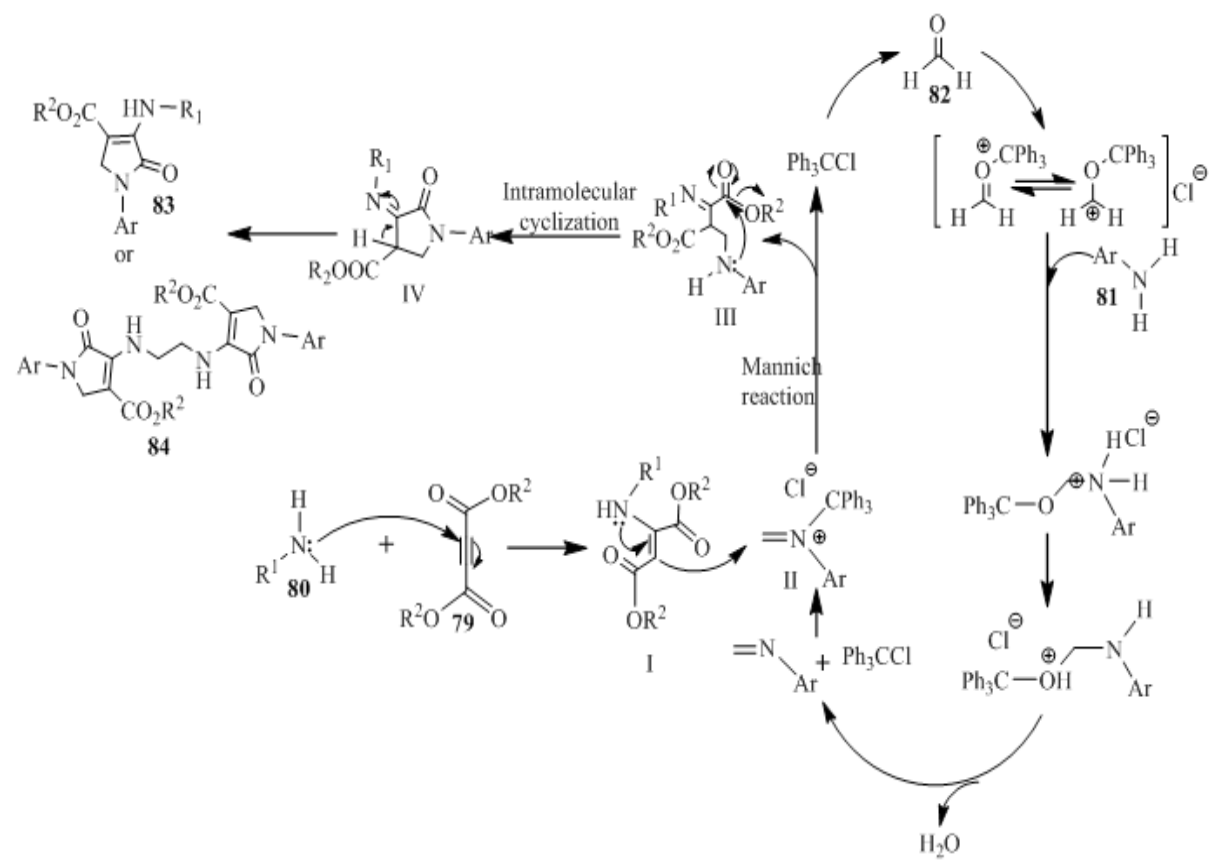

Fig. 11. Proposed mechanism for the above reaction

Hanuman et al., reported the tried to reaction methyl 2-isocyanoacetate 85 with unsaturated ketone 86 in the presence of $\mathrm{Cul}$ in choline hydroxide as a base, at room temperature for $1 \mathrm{~h}$ leading the formation of pyrrole derivative 87 with good yields (Scheme 18). A reasonable mechanism for this reaction is illustrated in Fig. $12 .{ }^{89}$ Initially the reaction of methyl 2-isocyanoacetate 85 with copper iodide in choline hydroxide gives $\alpha$-cuprioisocyanide $A$. Then, the 1,4-conjugate addition of $\alpha$-cuprioisocyanide A with chalcone 86 followed by intramolecular cyclization gives a cyclic organo-copper intermediate $B$ which on copper hydrogen exchange affords 3,4-Dihydro-2H-pyrrole $\mathrm{C}$. Oxidation of the latter offers the methyl 4-benzoyl-3-phenyl-1H pyrrole-2carboxylate.2,3,4-Trisubstituted $1 \mathrm{H}$-pyrroles 87 have important applications in the pharmaceutical and agrochemicals industries. 


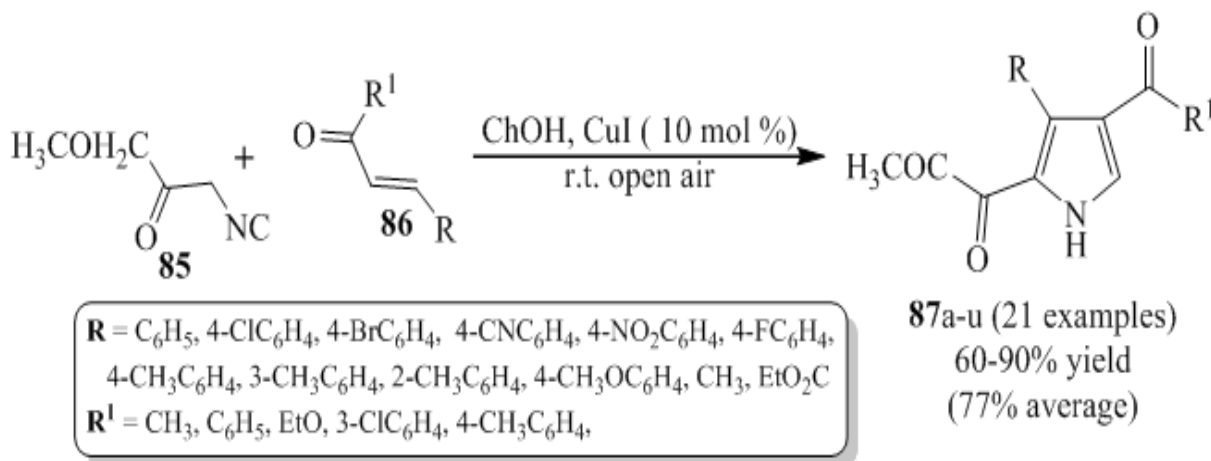

Scheme 18. Synthesis of pyrrole derivative

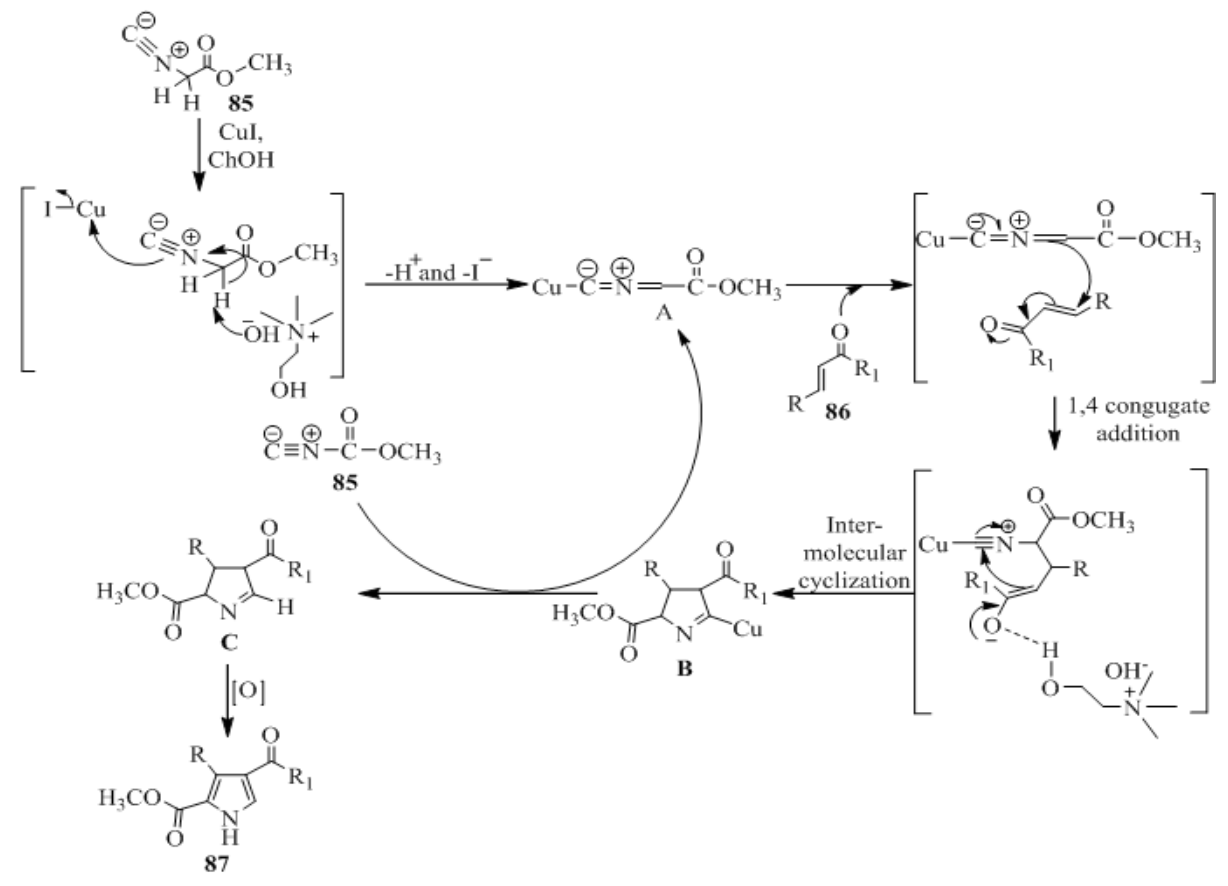

Fig. 12. Proposed mechanism for the formation of pyrrole derivatives

P. B. Jagadhane et al., reported the one pot three component synthesis of pyrrole derivatives 91 as shown in scheme 19 by using catalytic amount of iodobenzene and oxone $\left(2 \mathrm{KHSO}_{5} \cdot \mathrm{KHSO}_{4} \cdot \mathrm{K}_{2} \mathrm{SO}_{4}\right)$ as an environmentally safe and cheap terminal oxidant. ${ }^{90}$ It has been reported that when iodobenzene and oxone react, an active iodine species called hydroxyl (phenyl) iodonium ion is generated in situ. This active iodine species, hydroxyl (phenyl) iodonium ion, is used to catalyze the reaction between amine 88 , nitro-compounds 89 and $\beta$-diketone 90 . This experimental strategy was very simple and easy to achieve making, this protocol an important synthetic strategy for the synthesis of pyrroles.

An operationally simple metal free one-pot four-component synthesis of spiro[indoline-3, 4,0-pyrano [2,3-c]pyrazoles] 96 has been introduced by $\mathrm{C}$. Wang et al., by using cost effective and easily available materials, viz., hydrate hydrazine 92 , isatin 94, dimethyl acetylene dicarboxylate 93 and malononitrile or ethyl cyanoacetate 95 (Scheme 20)..${ }^{91} \mathrm{~A}$ four component reaction is proposed using Huisgen's 1,4-dipole, ethanol is used as a solvent and triethyl amine as a promoter. The products are obtained in good yields. 


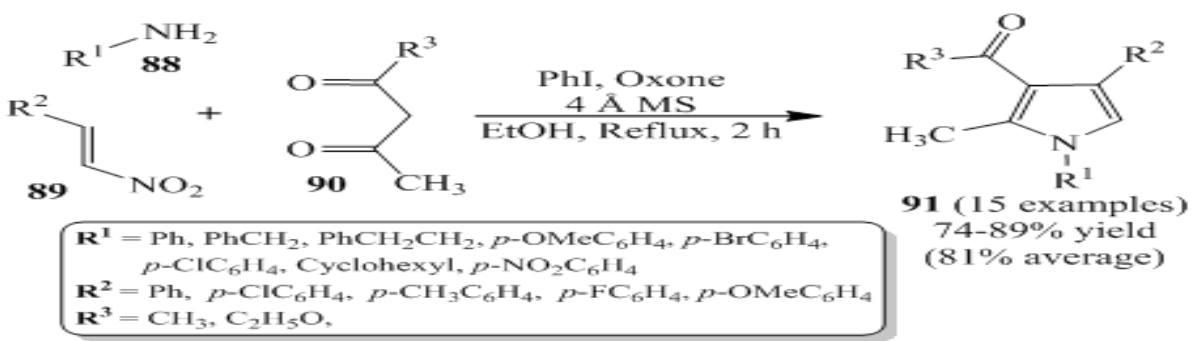

Scheme 19. One pot three component synthesis of substituted pyrrole

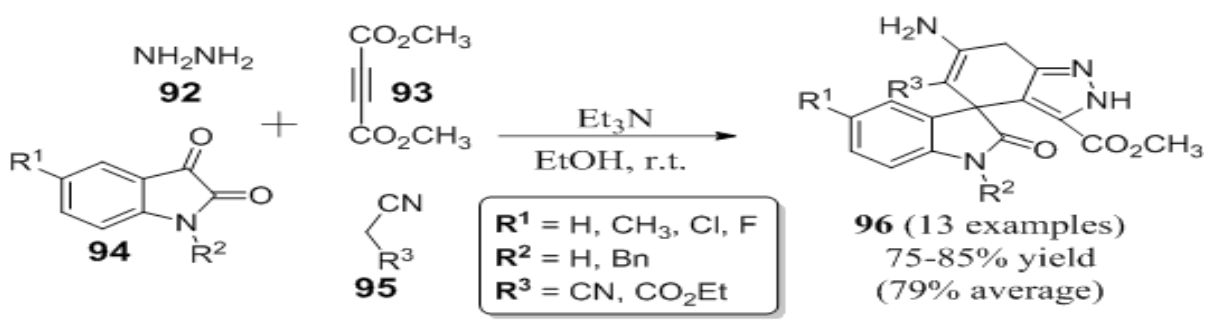

Scheme 20. One pot four component synthesis of pyrano-pyrazoles derivative

Recently, an exclusive one-pot synthesis of fused pyridine and pyrrole derivatives 100 and 102 was developed by the Mishra et al., (Scheme 21). They used very cheap and easily available reactants like arylglyoxal monohydrate 97 , 4-hydroxy coumarin 98, 3-amino-5-methylpyrazole 99. ${ }^{92}$ For the synthesis of fused pyridine derivatives 100 and for the synthesis of the pyrrole derivatives 3 -amino coumarin 101 was used in the place of 3-amino-5-methylpyrazole 99 in acetic acid, under $\mathrm{MW}$ heating for $30 \mathrm{~min}$. at $130^{\circ} \mathrm{C}$ (Scheme 21). The mechanistic pathway for this protocol shows that initially, Knoevenagel condensation and isomerization takes place to produce an intermediate which then, undergoes intra molecular cyclization followed by tautomerization to gives the final product.

An, effective and regioselective protocol for the synthesis of benzo-indoles 106 was reported by the J. Wei et al., through an unexpected one-pot three component reaction of readily available starting material saryl-glyoxals 103, cyclic 1,3-dicarbonyls 104 and naphthalen-2-amine 105 under microwave irradiation at $70^{\circ} \mathrm{C}$ (Scheme 22). ${ }^{93}$<smiles>O=c1oc2ccccc2c(O)c1-c1c(-c2ccccc2)[nH]c2c(=O)oc3ccccc3c12</smiles>

102 (05 examples) $92-95 \%$ yield ( $94 \%$ average)<smiles>Nc1cc2ccccc2oc1=O</smiles>

101 $\mathrm{AcOH}, \mathrm{MW}$

$\mathbf{R}^{1}=\mathrm{H}, \mathrm{F}, \mathrm{OMe}$ $\mathbf{R}^{2}=\mathrm{H}, \mathrm{Me}$<smiles>[R][X]1=CC=CC(C(=O)C(O)O)C1</smiles><smiles>[R]c1cccc2c(O)cc(=O)oc12</smiles>
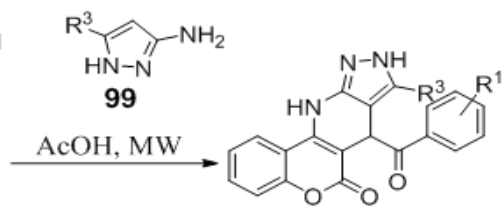

100 (08 examples) $85-97 \%$ yield ( $92 \%$ average)

Scheme 21. One-pot three component synthesis of fused-pyrrole and pyridine derivatives

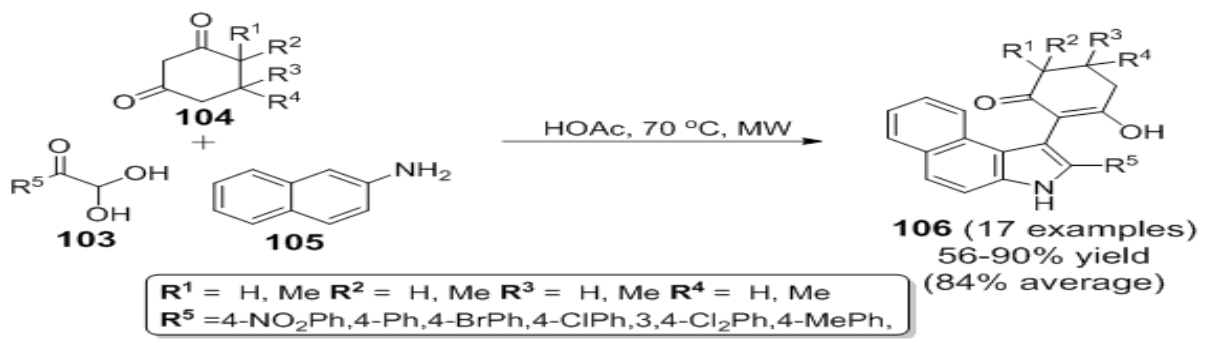

Scheme 22. One-pot three component synthesis of benzo-indoles derivatives 
Till date only a few protocols have appeared in the literature on the catalyst free synthesis of penta-substituted pyrrole derivatives. Recently, Gandhi et al., reported an attractive catalyst free eco-friendly one-pot four component synthesis of penta-substituted pyrrole and dihydro-1 $\mathrm{H}$ pyrrole derivatives 111 from inexpensive starting materials like phenyl glyoxal monohydrate or ethyl glyoxalate 107, N, N dimethyl barbituric acid 109, 1,3-Dicarbonyls 110 and amines 108 in the presence of ethanol (Scheme 23). ${ }^{94}$ This reaction was performed for $1-12 \mathrm{~h}$ at reflux temperature. The pathway for the synthesis involves a Knoevenagel condensation and intramolecular cyclization leading to the formation of pyrrole derivative. This method can serve as an excellent alternative to existing methods for the synthesis of penta-substituted pyrrole because the pure product was obtained by simple filtration and washing, without the use of column chromatography.

Karamthulla et al., reported a new protocol for the preparation of novel pyrrolo[2,3-d]pyrimidine derivatives 115 via the nucleophilic addition, aromatization and Knoevenagel condensation of phenyl glyoxal monohydrate 112, 6-amino-1,3dimethyluracil 113 and malononitrile 114. In their report, they disclosed two procedures for the preparation of pyrrolo[2,3-d]pyrimidine derivatives (Scheme 24). ${ }^{95}$ In method-A, they used ethanol as a solvent under reflux which led to the formation of desired product after 5-8 $\mathrm{h}$ in excellent yields. On the other hand in method-B, they performed the reaction under microwave heating condition at $80^{\circ} \mathrm{C}$ and observed that the final product was obtained within $15 \mathrm{~min}$. with appropriate good yield.

They also reported another one-pot three component reaction in which 2-mercaptopyrimidine 116 was used instead of malononitrile 114. This reaction was performed under microwave irradiation in the presence of an acidic catalyst at $120^{\circ} \mathrm{C}$ for $20 \mathrm{~min}$. leading to the formation of the desired product 117 in excellent yields.

Man etal., have developed a chemoselective, regioselective and stereoselective environmentally benign approach for the synthesis of furo[2,3-b] pyrroles derivatives 121 via one-pot three component cycloaddition of benzoyl thioamide 120 , phenyl glyoxal 118 , and ethyl cyanoacetate $119 \mathrm{in} \mathrm{EtOH}$ at $40^{\circ} \mathrm{C}$ for $6 \mathrm{~h}$ in the presence of 0.5 equiv. of $\mathrm{N}, \mathrm{N}$-di-isopropyl ethylamine (DIPEA). The desired product 121 was obtained in moderate yields. This protocol is a wide substrate scope (Scheme 42). ${ }^{96}$

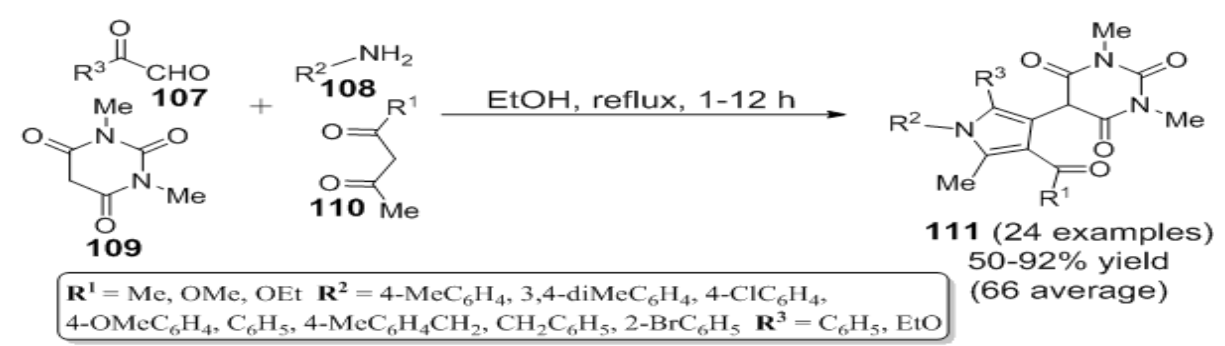

Scheme 23. One pot four component synthesis of penta-substituted Pyrrole derivatives

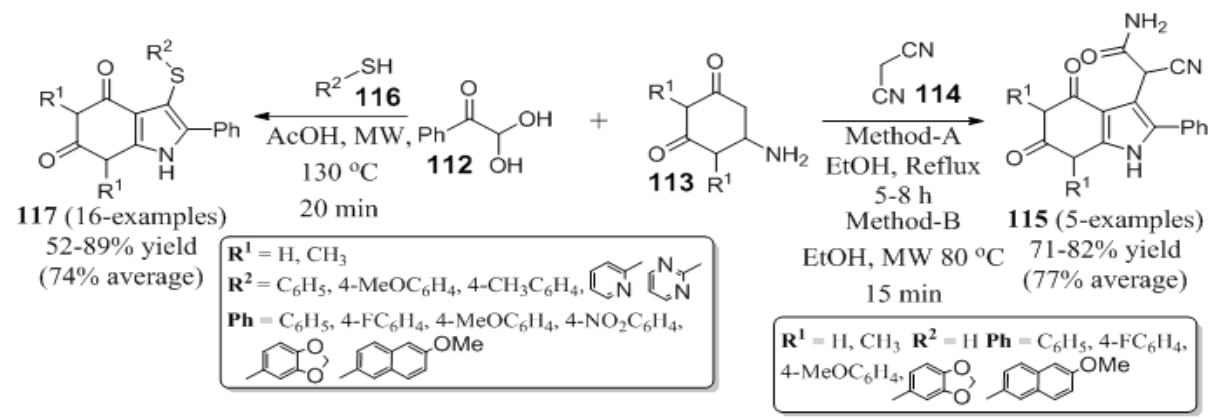

Scheme 24. One pot three component synthesis of pyrrole-pyrimidine derivatives 


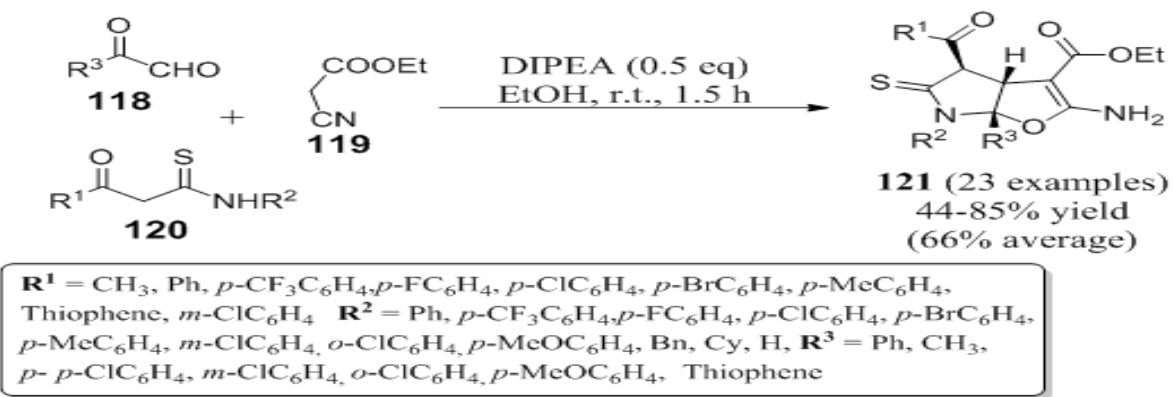

Scheme 25. One pot three component synthesis of furo-pyrroles derivatives

In 2013, Tripoteau et al., synthesized N-aryl pyrrole derivatives 124 from the reaction of arylnitroso compounds 123 with borylated dienes 122 in $5 \mathrm{~h}$ at room temperature (Scheme 6). ${ }^{97}$ The mechanistic pathway is thought to involve a regioselective nitroso Diels-Alder cyclization reaction. It is remarkable that no pyrrole formation was observed if the cycloadduct is stable on the way to hydrolysis, as incase for the MIDA derivatives. Hence, tri-coordinated $\mathrm{sp}^{2}$ boron species are required for ring contraction of the oxazine and the desired $\mathrm{N}$-aryl pyrrole derivatives were obtained with mild to good yields.

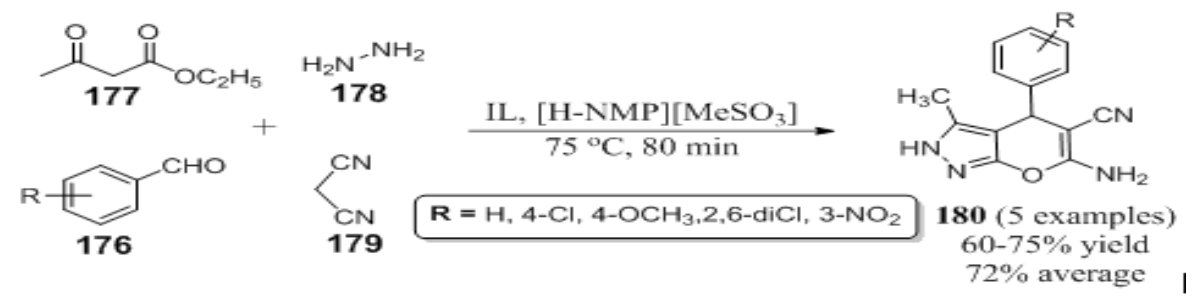

Scheme 26. One pot two component synthesis of $\mathrm{N}$-aryl pyrrole derivatives

An efficient, economical, eco-friendly and convenient route had been reported by Dhinakaran et al., for the synthesis of tetrahydro pyridines 129 and polysubstituted pyrroles 128 via a one pot three component reaction of 2,2-dihydroxy-1arylethan-1-one 125, malononitrile 126 and ethyl
(E)-3-(4-arylamino) acrylates 127 under catalyst and solvent free conditions by using the grinding method (Scheme 27). ${ }^{98}$ During their experiment they observed that the chemoselectivity of the reaction depends on the substitution on the $\mathrm{N}$-phenyl ring of ethyl (E)-3-(4-arylamino) acrylates (Figure 13).

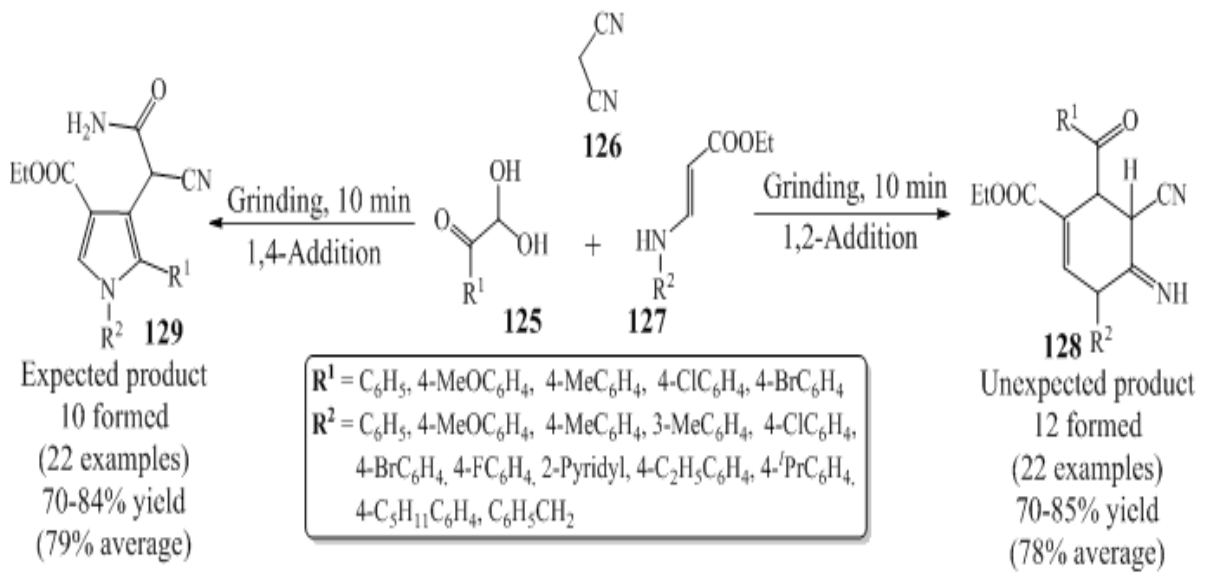

Scheme 27. One pot three component synthesis of pyrrole and pyridines by grinding method 


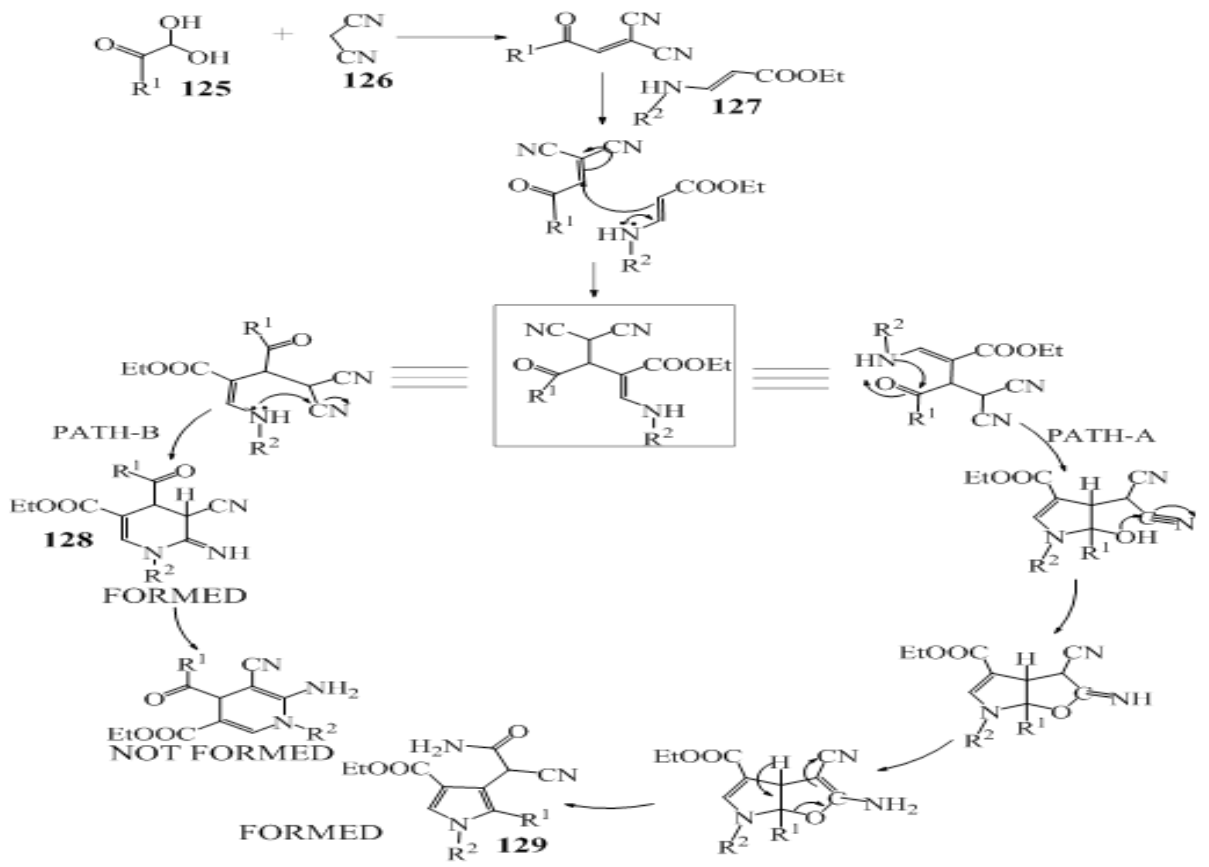

Fig. 13. Possible mechanism for the formation of Pyridine 128 and Pyrrole 129

Gabrielli et al., have developed a simple and efficient strategy for the synthesis of tetra-substituted pyrroles 132 by using a one pot Friedel-Craft elimination process involving pyrrole derivative 131 and the $\beta$-nitroacrylate 130 to give an intermediate which was reduced using heterogeneous catalyst to give the pyrrole derivative 132 with good yields(Scheme 28, Figure 14). ${ }^{99}$

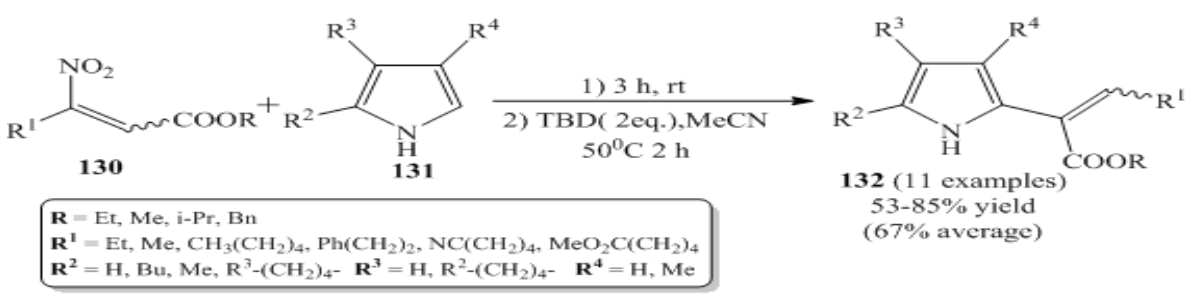

Scheme 28. One-pot two-component synthesis of penta-substituted pyrrole

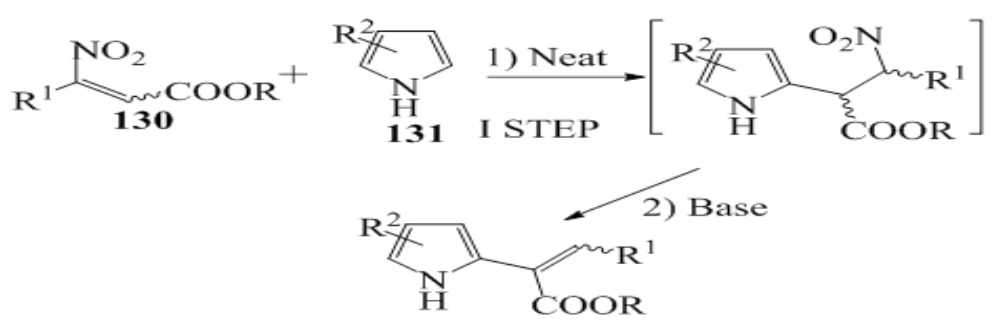

Filtration and evaporation

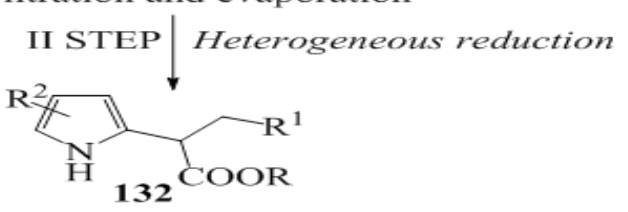

Fig. 14. Proposed mechanistic pathway for scheme 28 
Recently, the synthesis of diversely substituted pyrrolo[2,3-d]pyrimidine derivatives 137 was reported through an efficient one-pot two-step reaction by $\mathrm{M}$. Leonardi et al., They first prepared $\alpha$-iodoketones 134 from ketones 133, $\mathrm{N}$-iodo succinimide and toluene sulfonic acid under high-speed vibration milling for $1 \mathrm{~h}$ (Scheme 29). They then coupled active methylene compounds 135 and 2,2-dimethoxyethylamine 136 in the presence of $\mathrm{Ce}(\mathrm{IV})$ ammonium nitrate (CAN) for 20 min. to obtain the enaminone intermediate, followed by the addition of $\alpha$-iodoketones and silver nitrate whence after
$60 \mathrm{~min}$. the desired substituted pyrrole derivatives 137 were obtained in excellent yield. ${ }^{100}$ Furthermore, in severe acidic conditions they observed a cyclization at the C-5 position of compound 137. Therefore, they performed second step in dichloromethane and used an excess of aluminum trichloride, in the presence of trimethyl silyltriflate (TMSOTf) leading to the formation of pyrrole $[2,1-a]$ isoquinolines derivatives 138 in excellent yield. In this protocol, two rings and four new bonds are formed by a new Pomeranz-Fritsch-type reaction (Figure 15).

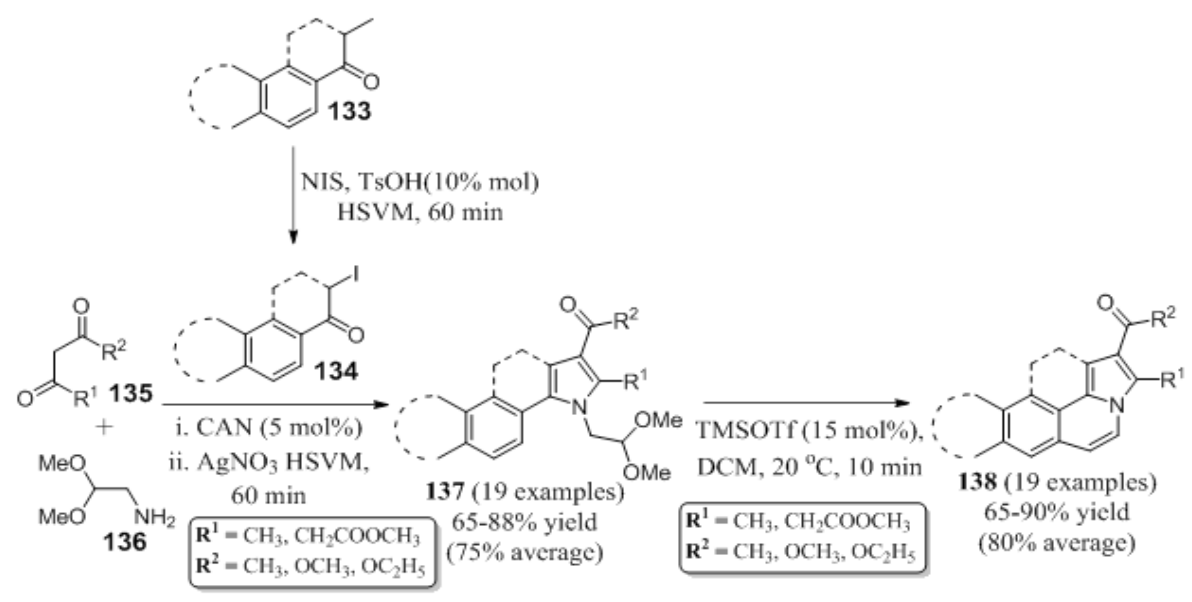

Scheme 29. One pot three component synthesis of pyrrole-pyrimidine derivatives

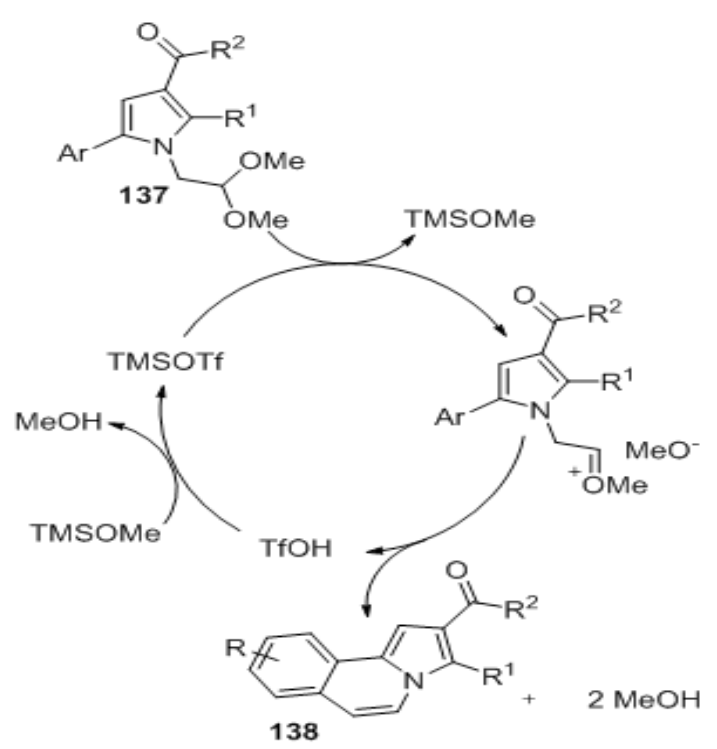

Fig. 15. Proposed mechanistic pathway for scheme 29

Li et al., synthesized a diverse library of regioselective spirocyclicoxindole-butenolides derivative 144 via a one-pot three component reaction using isatin 140, isocyanide 139 and allenoate 143 in toluene at $100^{\circ} \mathrm{C}$ for $18-72$ hours. The formation of spirocyclicoxindole-butenolides derivative proceeds through a $[2+2+1]$ cycloaddition (Scheme 30). ${ }^{101}$ In this protocol, a ring is formed with the formation of one $\mathrm{C}-\mathrm{C}$ and one $\mathrm{C}-\mathrm{O}$ bond. Another three component, one-pot method for the regio- and stereoselective synthesis of complex spirooxindoles derivatives 142 was investigated by $Z$. Tang et al., involving the bicyclization of allenoate derivative 141, isatin 140 and isocyanide 139 in toluene at reflexing temperature as shown in Scheme $30 .{ }^{102}$ This reaction proceeded through Michael addition, double cyclization, double [1,5]-hydride shift, and nucleophilic addition reaction. Sequence in which two new rings and one $\mathrm{C}-\mathrm{C}, \mathrm{C}-\mathrm{O}$, and $\mathrm{C}-\mathrm{N}$ bond were formed. Mild reaction conditions, high atom economy, and wide substrate scope make this synthetic protocol superior to its predecessors. The potential biological application of spiroxindoles serves as a catalyst for the development of new routes for their synthesis. 

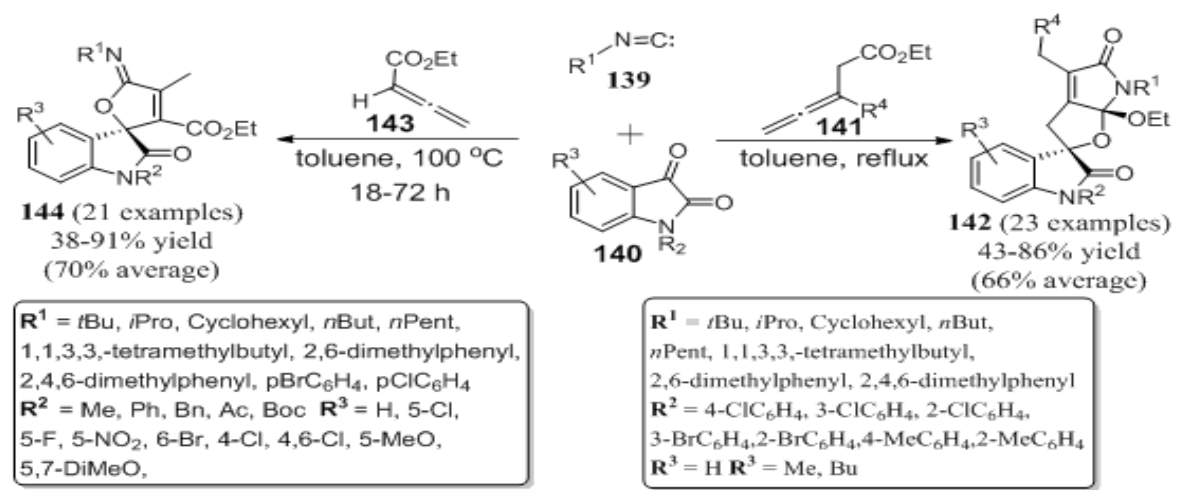

Scheme 30. One pot three component synthesis of complex spirocyclicoxindole-butenolides

An efficient and convenient route developed by K. B. Manjappa et al., has paved the way for the synthesis of multi-functionalized spiro-pyrrolizidines 149 or pyrrolizinones 148 by a one-pot three component reaction of L-proline 145, benzaldehyde 146 and 1,3-indanedione 147 via a catalyst free procedure under microwave irradiation. The reaction gave satisfactory results with various compounds (Scheme 31$).{ }^{103} \mathrm{~S}$ piropyrrolizidines 149 or pyrrolizinones 148 formation was proceeds via condensation, Michael addition, and a cyclization sequence.

Tian and co-worker. in 2015 published their work on utilization of isocyanide 150 and methylene indolinone derivatives 151 for the synthesis of complex spiro-oxindole derivatives 154 in the presence of indium trichloride as a catalyst through novel multiple isocyanide insertions, Michael addition, cyclization, and imine-enamine tautomerization reaction (Fig. 16). ${ }^{104}$ This method can serves as an excellent, atom economical, synthetic route for construction of complex spirooxindole (Scheme 32). In 2016 the same research group reported a new facile route for the synthesis of complex polycyclic derivatives 152 and 153 through a double isocyanide insertion ring opening, cyclization and isomerization sequence, by utilizing isocyanide 150 and methylene indolinone derivatives $151,{ }^{105}$ in the presence of $\mathrm{KAuCl}_{4}$ (15 mol \%) under reflux (scheme 32, Fig. 16). Additionally, they also observed a rare oxygen migration when the reaction was conducted at lower temperature $\left(95^{\circ} \mathrm{C}\right)$.
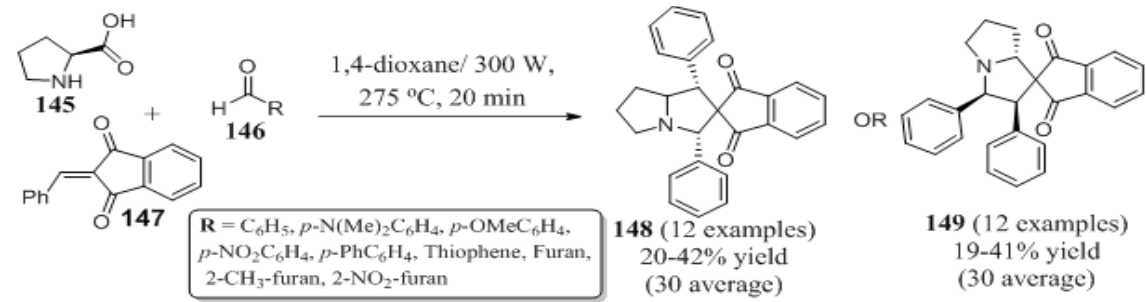

Scheme 31. One pot three component synthesis of spiro-pyrrolizidines or pyrrolizidiones

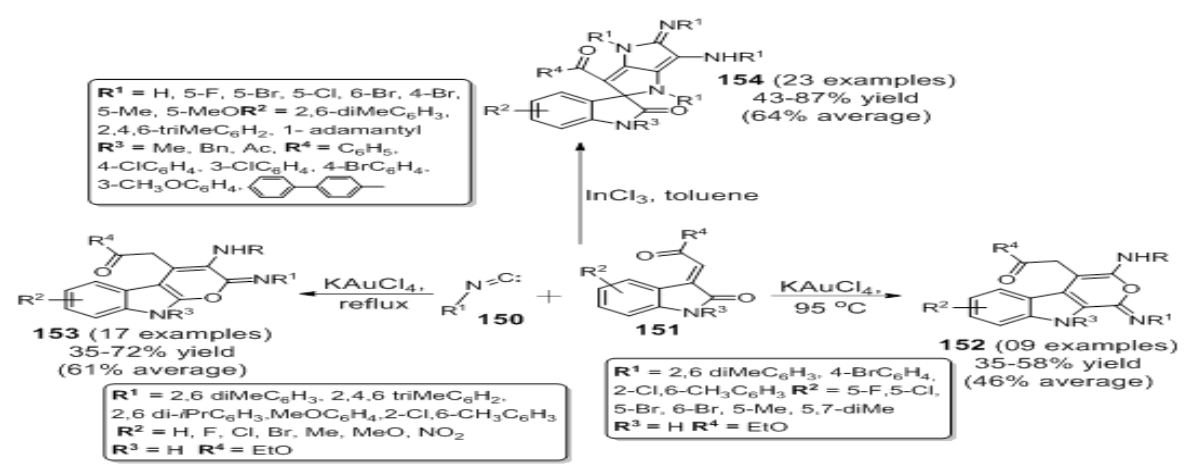

Scheme 32. One pot two component synthesis of complex spiro-oxindole derivatives 

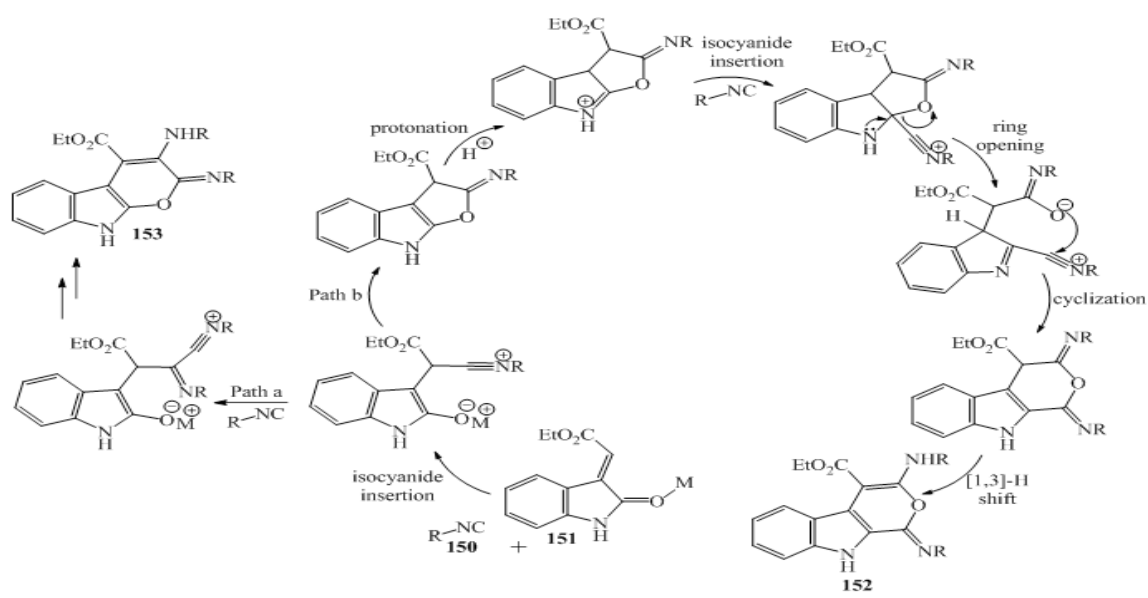

Fig. 16. Mechanistic representation of scheme 32 as proposed by the Y. Tian et al.,

In 2016, an efficient regioselective and stereoselective three component pathway was developed by Gein et al., for the synthesis of novel highly substituted bicyclo [2.2.2] octane derivatives 158. ${ }^{106}$ The prominent domino process involved an annulation followed by the reaction between aromatic aldehyde 156, substituted aniline 155 and aceto-acetanilide 157 in ethanol (Scheme 33). They obtained satisfactory results in the presence of bismuth nitrate (10 mol\%) at room temperature. After $30 \mathrm{~min}$. the desired product was obtained in good yield. Generally, one-pot synthesis of aldehyde and aniline gives substituted pyrrole derivatives but in this process bicyclo [2.2.2] octane derivatives were obtained due to the presence of bismuth nitrate as a catalyst.

Now a days many researchers are working towards the development of multi-targeted drugs. Pyrroles are highly valued scaffolds in the realm of medicinal chemistry and drug discovery. Consequently, a lot of work is being done towards the structural modification as well as the development of efficient new routes for the derivatization of pyrroles. In this context, Wu et al., recently proposed a one-pot synthesis of functionalized pyrrole derivatives, 2,6-disubstituted 9-arylcarbazoles 160 and 1,2,4-triaryl-substituted pyrroles 162 (Scheme 33). ${ }^{107}$ The reported experimental procedure, utilized commercially available low-cost reactant, anilines 155 and cyclohexanones 159 in metal-free conditions leading to the formation of 2,6-disubstituted 9-arylcarbazoles 160 in high yields. For the synthesis of 1,2,4-triaryl-substituted pyrroles 162, acetophenones 161 were used in place of cyclohexanones 159. Both reactions were performed under air in the presence of KI. This new method offers simple, fast and attractive procedure over the previous syntheses. Recently, Fleige and Glorius working for the synthetic precedent of Atorvastatin, published an article on the one-pot three-component synthesis of 1,2,4-trisubstituted pyrroles 165 by using simple starting materials, glycol-aldehyde dimer 164 , various chalcones 163 and p-toluidine 155. Satisfactory yield of pyrroles 165 was obtained by using thiazolium salt (20 mol\%) and $\mathrm{K}_{3} \mathrm{PO}_{4}(20 \mathrm{~mol} \%)$ in methyl cyanide. ${ }^{108}$ Furthermore, this protocol exhibited several benefits like mild reaction condition, operational simplicity, low catalyst loading, chemo, regio, and stereoselectivity in product. Mechanistically this reaction has attracted attention due to the use of Stetter-type hydroformylation/Paal-Knorr synthesis.

Cores et al., standardized an effective and cheap methodology for the synthesis of highly substituted pyrrole 169 with the help of $\beta$-dicarbonyl compound 167 , amine 166 and $\alpha$-haloester 168 . This reaction uses $\mathrm{InCl}_{3}$ as a catalyst and was performed at room temperature for the first $30 \mathrm{~min}$. and then in a microwave for $30 \mathrm{~min}$. at $120^{\circ} \mathrm{C}$ (Scheme 34). ${ }^{109}$ The mechanistic pathway of this synthesis shows a Hantzsch-like reaction. 


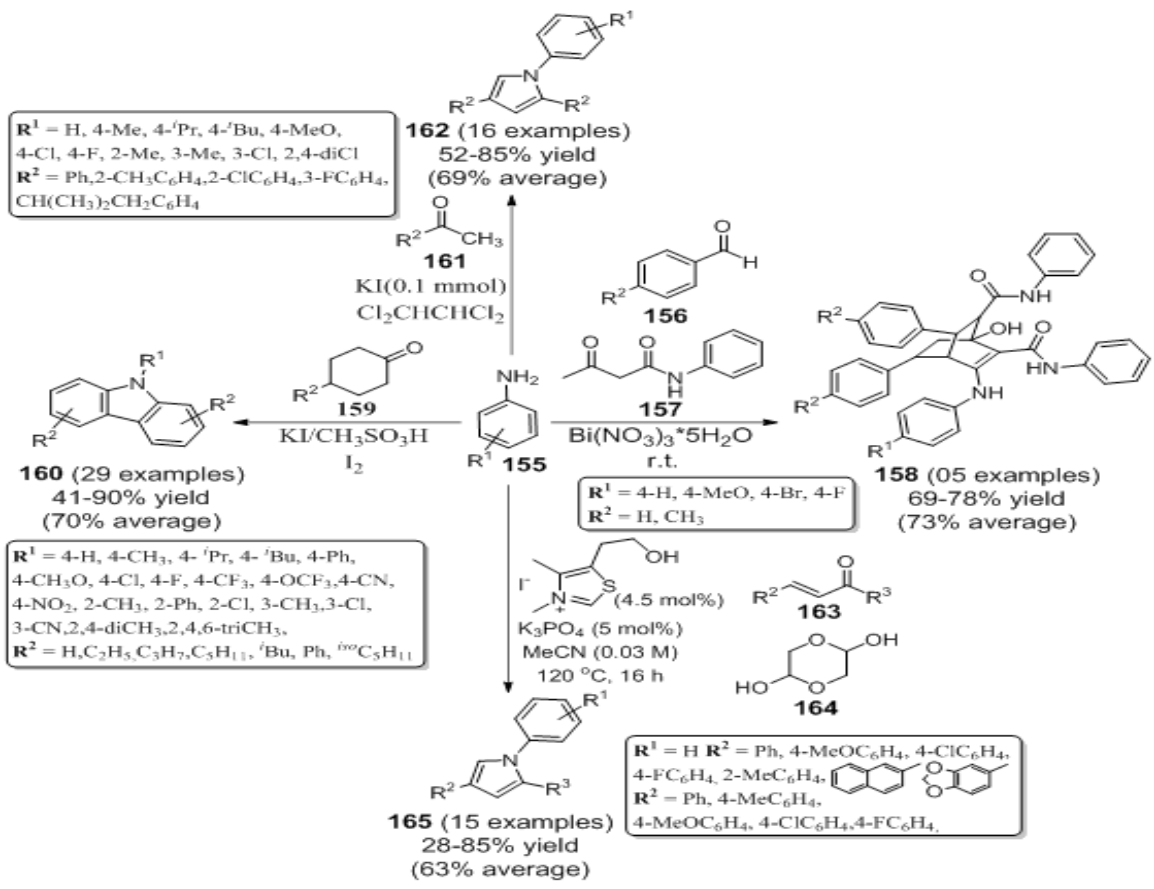

Scheme 33. One-pot synthesis of substituted bicycle-octane and pyrrole derivatives

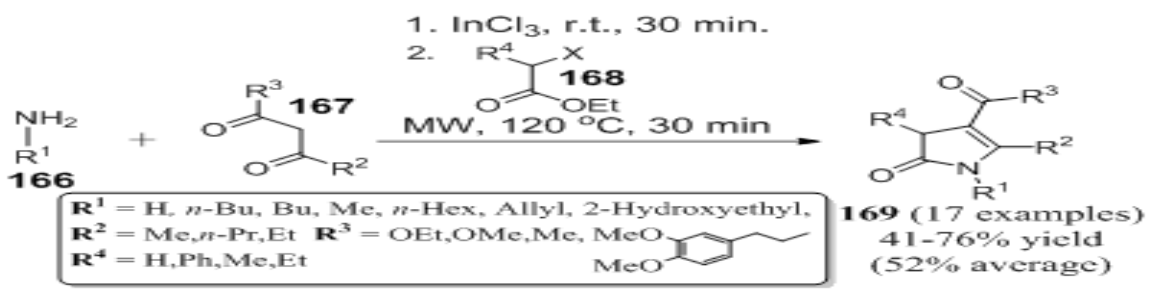

Scheme 34. One pot three component synthesis of highly substituted pyrrole

An environmentally benign, one-pot pseudo-five-component reaction was reported by Banerjee and co-worker for the synthesis of 4,4'-(arylmethylene) bis (3-methyl-1-phenyl$1 \mathrm{H}$-pyrazole-5-ols) 175 through the reaction of $\beta$-ketoesters 170 and 171, phenyl hydrazines 173 and 174 and aldehyde $172 .{ }^{110}$ in the presence of $\mathrm{K}_{2} \mathrm{CO}_{3}(50 \mathrm{~mol} \%)$ as a catalyst, in $\mathrm{MeCN}$ at room temperature leading to the formation of the desired product in excellent yields (Scheme 35 ).

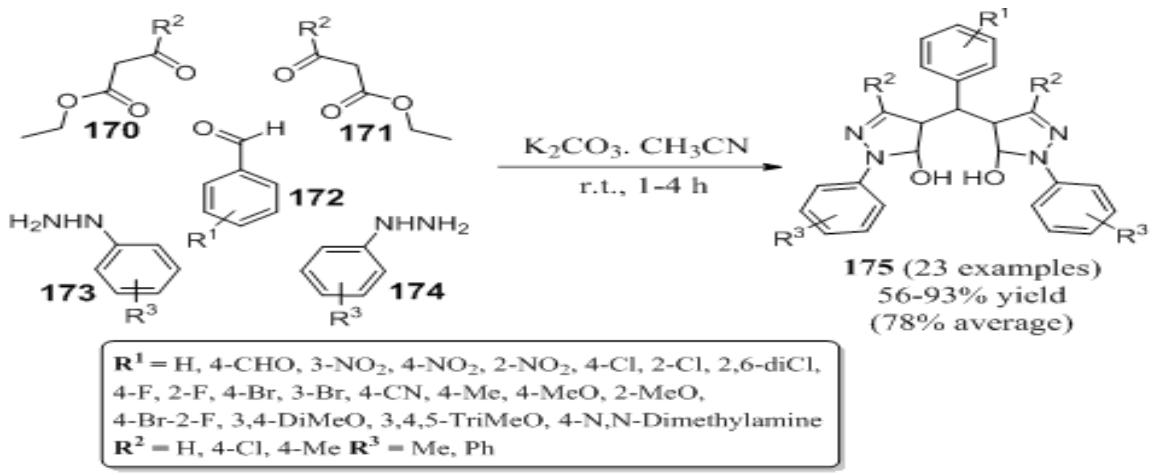

Scheme 35. Synthesis of 4,4'-(arylmethylene)bis(3-methyl-1-phenyl-1H-pyrazol-5-ols) derivatives 


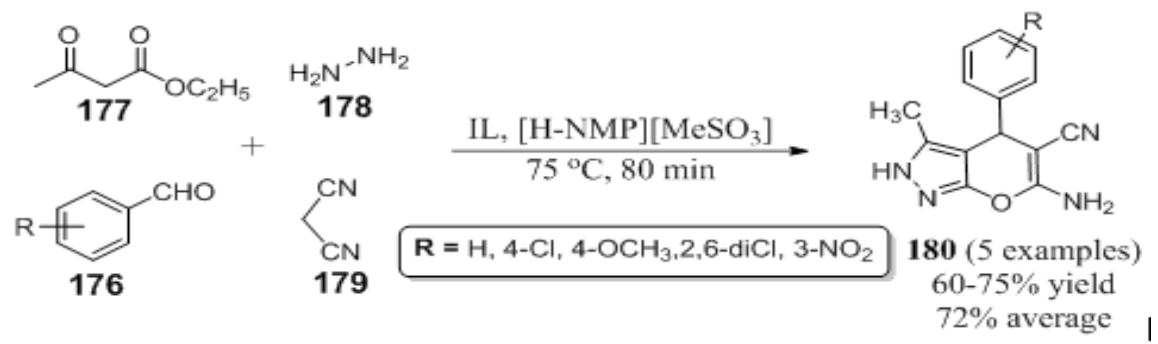

Scheme 36. Synthesis of penta-substituted pyrrole

Recently, Deshmukh and Hiwarale proposed a simple one-pot, four-component synthesis of the pyranopyrazole derivatives 180 by mixing aldehydes 176, ethyl acetoacetate 177 , hydrazine hydrate 178 and malononitrile 179 in the presence of ionic liquid and [H-NMP][MeSO ${ }_{3}$. The most important aspect of this protocol is the formation of the final product in good yield by simple filtration, eliminating the need for chromatographic purification (Scheme 36). ${ }^{111}$

Asghari et al., recently reported the synthesis of indolizines 184 using $4-\mathrm{N}, \mathrm{N}-$ dimethylaminopyridine (DMAP) 181, $\alpha$-halo-ketones 182 and dialkyl acetylene dicarboxylate (DMAD) 183 in dry THF at room temperature in $0.5-1 \mathrm{~h}$ (Scheme 37). The proposed mechanism for this transformation is shown in Fig. 17. ${ }^{112}$ On the basis of the chemistry of $\mathrm{N}$-heterocyclic nucleophiles, it is assumed that the zwitter ionic intermediate $A$ results from the initial addition of the amino pyridine to the dialkyl acetylene dicarboxylate. The nucleophilic attack of the intermediate $A$ on the halogenated carbon atom of the $\alpha$-halo ketone generates the salt intermediate $B$, which subsequently loses a proton to form the next intermediate $\mathrm{C}$. This zwitter ionic intermediate $C$ then undergoes cyclization to give intermediate $D$, which eliminates $\mathrm{HZ}$ to afford the indolizines 184.

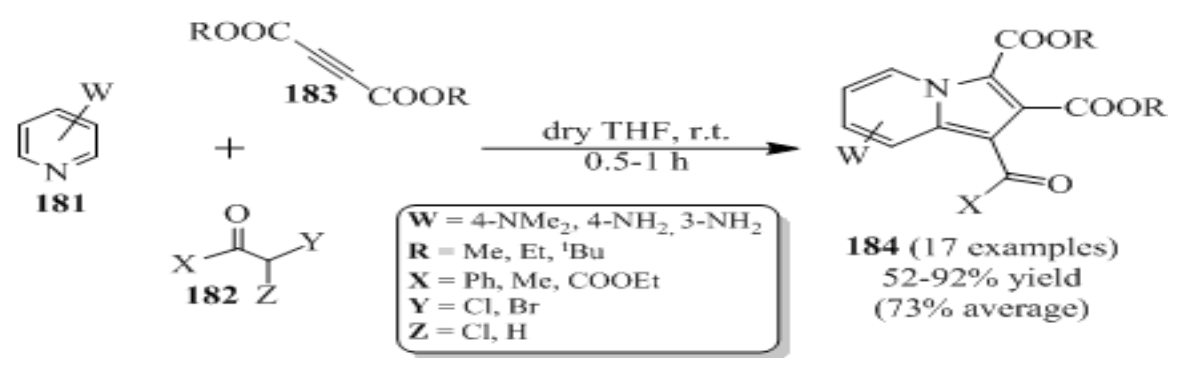

Scheme 37. Synthesis of fused-ring substituted pyrrole derivative

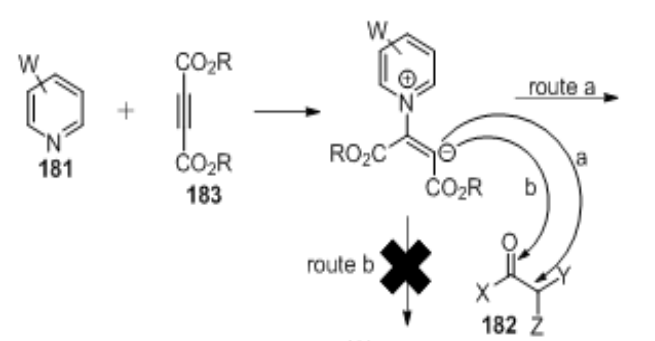

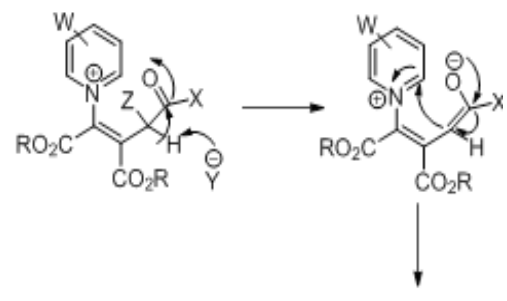

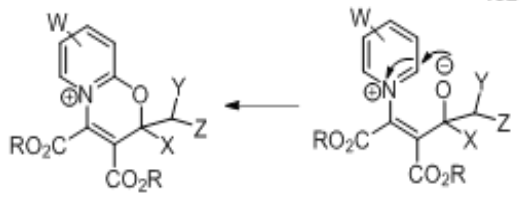

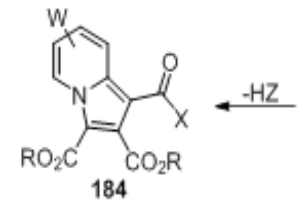

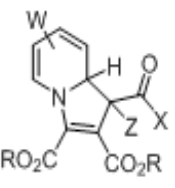

Fig. 17. Proposed mechanism for the synthesis of pyrrole derivatives 184 
Zheng et al., described the reaction of 1-phenylpropane-1,2-dione 185, 4-methoxyaniline (PMP) 186 and benzaldehyde 187 by using 4-methylbenzene-sulfonic acid monohydrate $(\mathrm{TsOH}$. $\mathrm{H}_{2} \mathrm{O}$ ) as a catalyst in DCM at room temperature to obtain the corresponding poly-substituted pyrrole 188 in moderate yield (Scheme 38 ). ${ }^{113} \mathrm{~A}$ plausible mechanistic pathway for this reaction was proposed wherein 1-phenylpropan-1,2-dione 185 and 4-methoxyaniline 186 led to the in situ formation of iminium intermediate which reacted with benzaldehyde 187 and 4-methoxyaniline 186, followed by the intramolecular nucleophilic attack by the amine to afford the amino-alcohol based intermediate in the presence of an acid catalyst (Fig. 18). After acid catalyzed tautomerization of the third intermediate to the corresponding enamine the protonated amino-alcohol loses a molecule of water to generate the relatively stable conjugate iminium ion followed by the removal of a proton to generate the target pyrroles 188 .

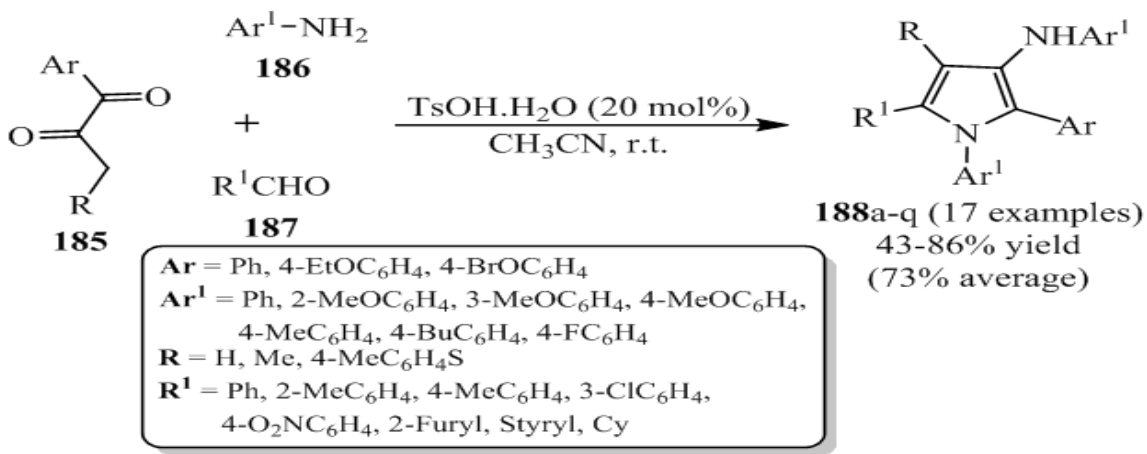

Scheme 38. One-pot three component reaction of pyrrole derivatives

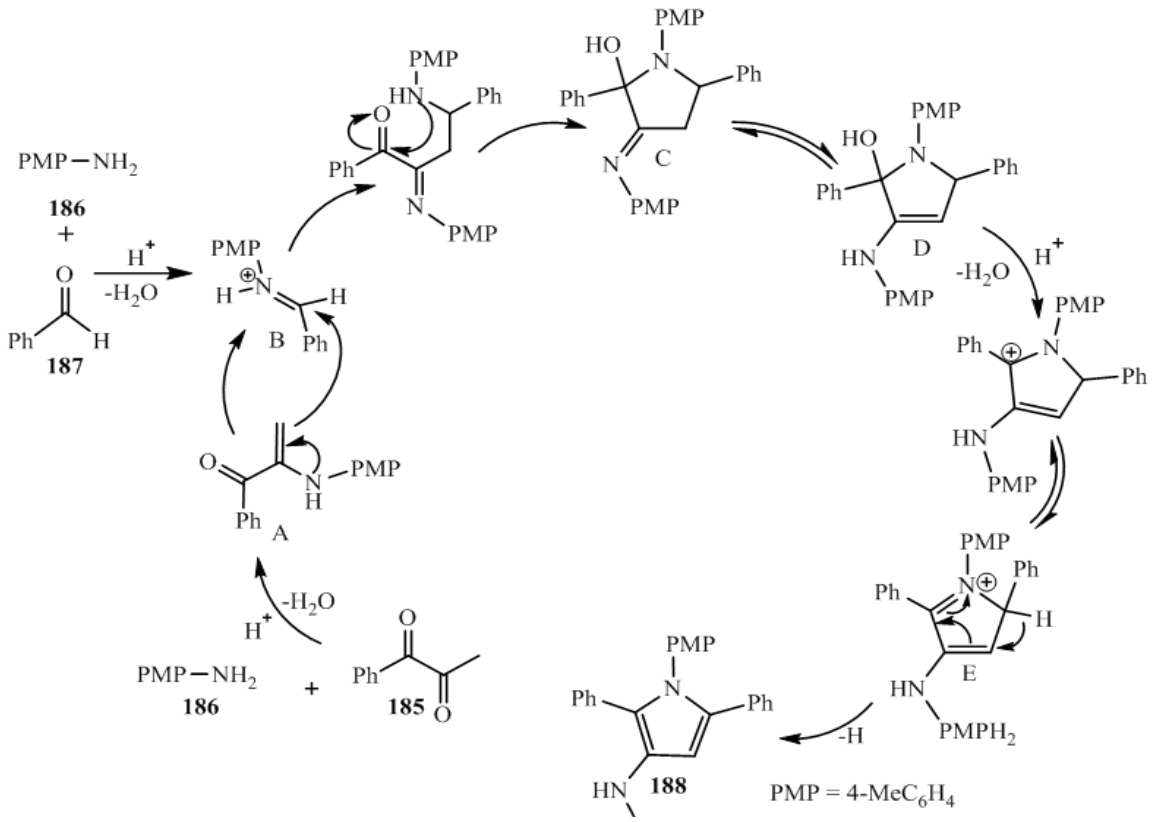

Figure 18. The possible mechanism of polysubstituted pyrroles ofscheme 27

Shahvelayati et al., reported an efficient one pot three component reaction of commercially available 1,3-dicarbonyl compounds 191, $\alpha$-haloketone 189 and amines 190 in the presence of ZnO-NPs (5-20\%), to obtain highly substituted pyrroles 192 with moderate to good yield. A tentative mechanism for this conversion has been suggested in scheme 39. ${ }^{114}$ An intermediate was 
initially produced by the reaction of 1,3-dicarbonyl compounds 191 and amines 190 which then reacted with $\alpha$-bromoketones 189 followed by cyclization to affords the target molecules 192.

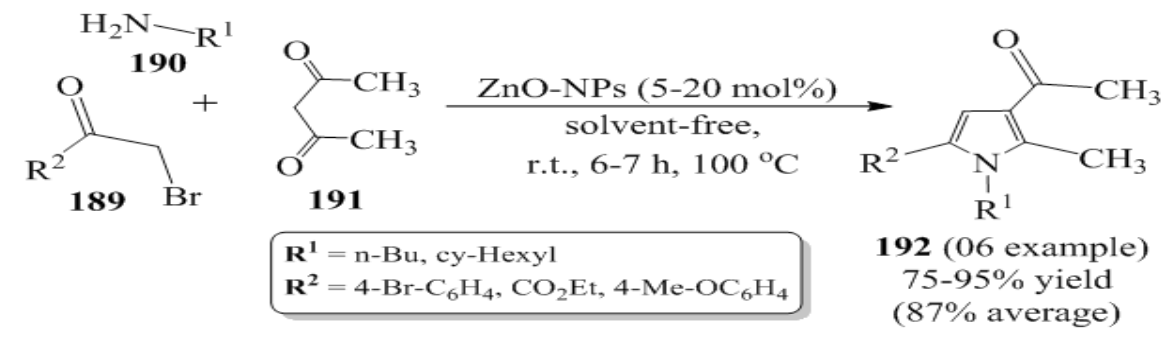

Scheme 39. Nano zinc oxide catalyzed one pot synthesis of $\mathrm{N}$-alkyl-3-acetyl-2-methylpyrrole

R. Raju et al., have proposed the metal free synthesis of substituted pyrroles 195 and 197 through the reaction of phenyl acetylene 193 with 2 -acyl aniline derivatives 194 and $\beta$-enamino ketone 196 respectively ${ }^{115}$ Based on their experimental observation, they suggested an lodine $/ \mathrm{K}_{2} \mathrm{CO}_{3}$ catalysed condensation for the formation of the pyrrole derivatives 195 and 197 as presented in scheme 40 . The attack of phenyl acetylene on keto group of 2-amino acetophenone 194 provides the first intermediate, followed by the activation of the alkyne group by lodine/and the displacement of iodine to provide the cyclic intermediate, which finally undergoes dehydration to give the desired pyrrole derivatives 195 and 197.

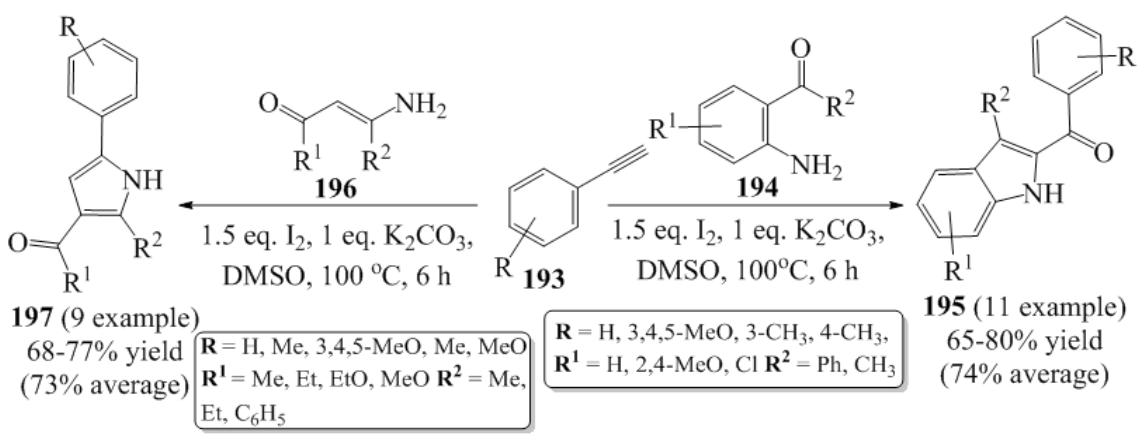

Scheme 40 . One pot two component synthesis of polysubstituted pyrrole derivative

In 2014, H. Mehrabi et al., developed a kinetically controlled, efficient and facile method for the synthesis of penta-substituted pyrrole derivatives 143 by reaction of alkyl acetoacetates 141 , dialkyl acetylene dicarboxylate 138 and amines 142 in the presence of acetic acid. The target compounds were obtained in excellent yields (Scheme 41). ${ }^{116}$ The proposed mechanism suggests that the reaction involved a nucleophilic addition, condensation, cyclization and, oxidation sequence to generate the desired products.

Similarly, in 2016, Mariappan and co-workers synthesized poly-substituted pyrrole 200 with the help of substituted monophenacylaniline 199 and dialkyl acetylene dicarboxylate 198 in DMF under microwave irradiation $(110 \mathrm{~W})$ at $110^{\circ} \mathrm{C}$ for $10 \mathrm{~min}$. as shown in scheme $41 .{ }^{117} \mathrm{In}$ this reaction, $\alpha$-amino ketone initially reacted with the electron deficient alkynes to afford an intermediate. Nucleophilic attack of this intermediate on the carbonyl group followed by the removal of water resulted in the desired product 200. The main advantages of this protocol were the short reaction times, catalyst free conditions and excellent yield of the products.

Zhao et. al., have reported another interesting, impressive and novel one-pot three-component approach for the synthesis of penta-substituted pyrroles 205 from nitroepoxides 204, primary amines 202 and dialkyl acetylene dicarboxylates 198 (Scheme 41). ${ }^{118}$ This protocol was performed under mild reaction conditions, without the use of any catalyst and the desired product was obtained in good yield. Gilbert et al., reported an exciting synthetic procedure for the synthesis of pyrrole 
derivatives 207. During their experiments they used Titanium imido precatalysts. The inter and intramolecular oxidative coupling of alkynes or enynes 206 with diazenes 198 in the presence of the aprotic catalyst $(\mathrm{py})_{3} \mathrm{TiCl}_{2}(\mathrm{NPh})$ led to synthesis of poly-substituted pyrroles $207 .{ }^{119}$ This reaction is a unique example of catalytic oxidative $\mathrm{C}-\mathrm{N}$ bond formation with a group 4 transition metal and of catalytic formal $[2+2+1]$ six-electron cyclization with a nitrene feedstock. In the same manner, Saleh and Voituriez proposed a simple and attractive protocol wherein they reacted indolecarbaldehyde 208 , phospholene (4-nitrophenyl) phosphate in freshly distilled degassed toluene in a Schlenk tube. Then, the di acetylene dicarboxylate 198 and phenylsilane were added using micro-syringes. The reaction mixture was then heated at $60^{\circ} \mathrm{C}$ for $16 \mathrm{~h}$ as shown in scheme $41 .{ }^{120}$ The entire procedure (cyclization /hydrolysis/oxidation) could be accomplished consecutively in a one-pot fashion, with remarkable yields up to $90 \%$. This procedure offers several advantages over the conventional protocols like mild reaction conditions, operational simplicity, minimum environmental impact and, facile product formation.

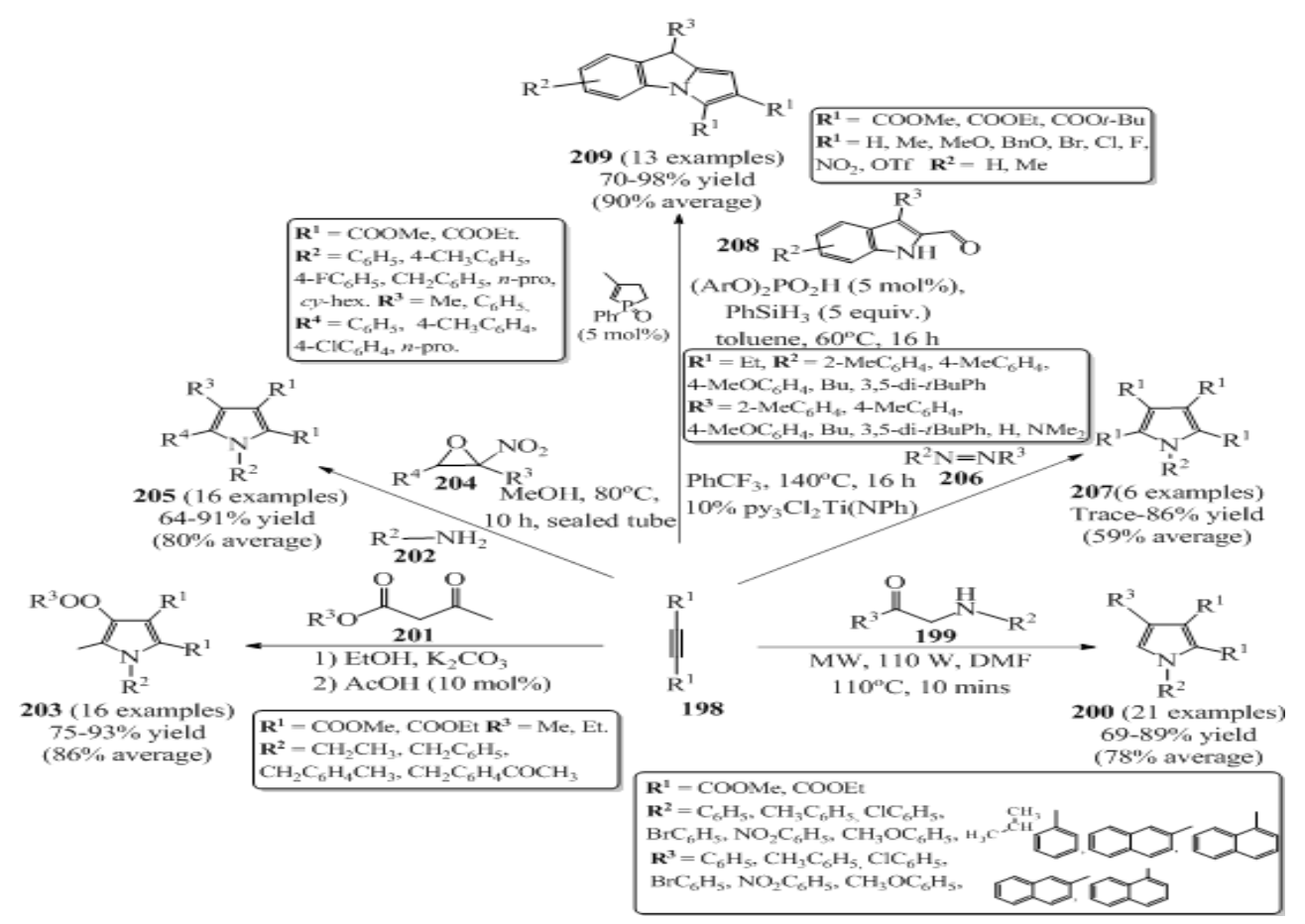

Scheme 41. One pot synthesis of different polysubstituted pyrrole derivative

Recently, N. R. Modugu and P. K. Pittala have established an novel, and efficient procedure for the synthesis of isoxazolyl dihydro- $1 \mathrm{H}$-indol$4(5 \mathrm{H})$-ones 213 , from diverse 4-amino-3-methyl-5styrylisoxazoles 211 , dimedone 212 , and differently substituted 2-chloroacetophenones 210 using $[\mathrm{HMIm}] \mathrm{BF}_{4}$ as a recyclable catalyst (Scheme 42). ${ }^{121}$ This strategy has attracted a lot of attention due to advantages like simple protocol, mild reaction conditions, eco-friendly credentials and excellent yield of products. Furthermore, the synthesized derivative exhibited interesting biological activity.

Panther and Muller reported an efficient four-component Heck isomerization-Fischer indolization-alkylation (HIFIA) synthetic procedure for the synthesis of 1-alkyl-3-benzylindoles derivatives 218 by using easily available starting materials such as hydrazines 214, (hetero) aryl bromides 215 , allyl alcohols 217, and alkyl bromides 216 under microwave irradiation (Scheme 43). ${ }^{122}$ This reaction mechanism offers several advantages over other conventional methods like short reaction times, easy handling, high yields and, chemo, regio- and stereoselectivity in the product.

A one-pot method for the synthesis of 5-aryl-3-methyl-1-phenyl-1,2-dihydro-7aHpyrazolo[3,4-c] pyridazin-7a-ol derivatives 222 was reported by M. Rimaz et al., involving Knoevenagel condensation and cyclization. In their investigation, they used arylglyoxal monohydrates 219, 5-methyl- 
2-phenyl- 2,4-dihydro-3H-pyrazol-3-one 221 and hydrazine hydrate 220 . They observed that the highest yield was obtained in acetonitrile in the presence of 1,4-diazabicyclo[2.2.2]octane (DABCO) in scheme 44. ${ }^{123}$

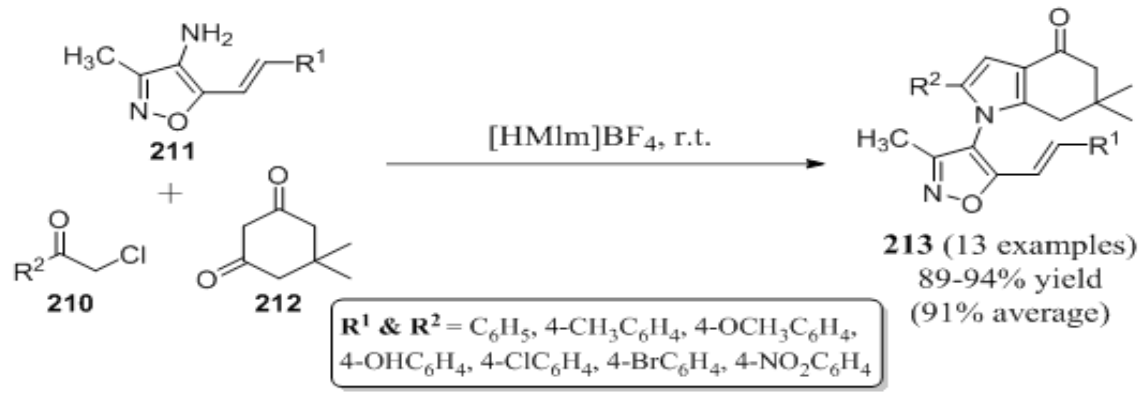

Scheme 42. One pot three component synthesis of isoxazolyldihydro- $1 \mathrm{H}$-indol-4(5H)-ones derivatives

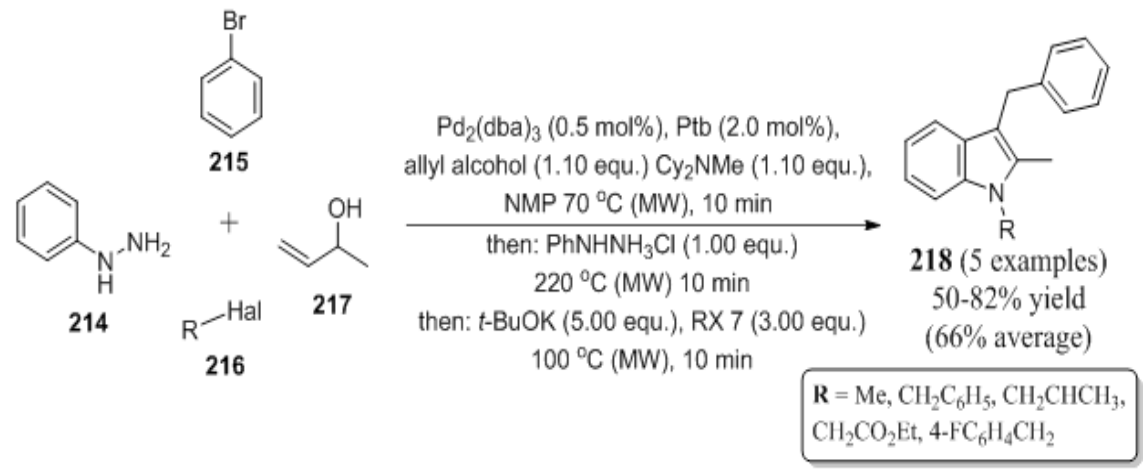

Scheme 43. One pot three component synthesis of substituted indole derivatives

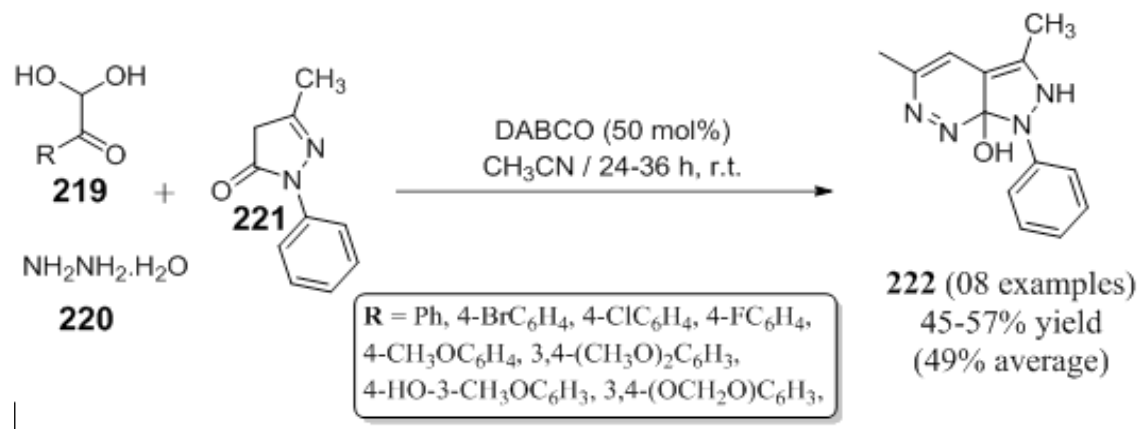

Scheme 44. One pot three component synthesis of pyrazolo-pyridazine derivatives

Recently, Daw et al., reported a new protocol by using pyridine based $\mathrm{PNNH}$ pincer co-complex as precatalyst in the presence of the base $\mathrm{NaHBEt}_{3}$ and $\mathrm{t}$-BuOK for the synthesis of the pyrrole derivatives 225 from diols 223 and secondary amines 224. In the presence of the co catalyst, the diols convert into diketone. However, due to the use of the transition metal catalyst, this procedure is considered less eco-friendly. ${ }^{124}$

In the same year Karami et al., also synthesized pyrrole derivatives 228 by using Paal-Knorr reaction in the presence of a metal based catalyst, molybedate sulfuric acid (MSA) in solvent free conditions, at $60^{\circ} \mathrm{C}$, by using diols 226 and secondary amines $227 . .^{125}$

Recently, the syntheses of diversely substituted pyrrolidine-fused heterocycles 232 were reported by Jiang et al., They reported for the first time, a one-pot three component reaction by using 
n-butyl isocyanides 229 , allenoates 230 , and imines 231 in water and toluene. In this synthesis, two rings and five chemical bonds were formed. Furthermore, four carbon atoms in allenoate were assimilated into the ring formation, which is quite rare, making this synthesis all the more significant (Scheme 47). ${ }^{126}$

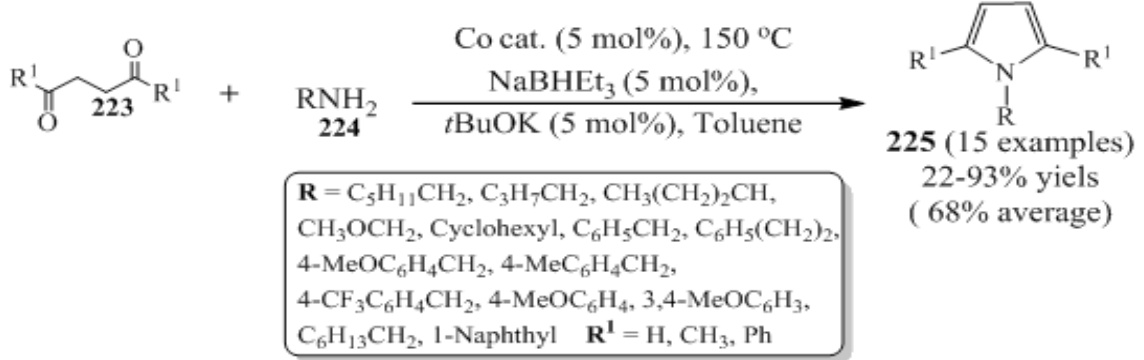

Scheme 45. One pot three component synthesis of pyrrole derivatives<smiles>[R12]NC([R])=O</smiles>

$227^{2}$
MSA (1 mol\%)

Solvent-free, $60^{\circ} \mathrm{C}$

$$
\begin{aligned}
& \mathbf{R}=\mathrm{C}_{6} \mathrm{H}_{5},-\mathrm{C}_{6} \mathrm{H}_{4}-, 5-\mathrm{Cl}-2-\mathrm{OHC}_{6} \mathrm{H}_{3}, 4-\mathrm{OHC}_{6} \mathrm{H}_{5}, \\
& 4-\mathrm{NO}_{2} \mathrm{C}_{6} \mathrm{H}_{5}, 4-\mathrm{MeC}_{6} \mathrm{H}_{4}, 4-\mathrm{ClC}_{6} \mathrm{H}_{4}, 4-\mathrm{ONH}_{2} \mathrm{C}_{6} \mathrm{H}_{4}, \\
& \mathrm{CH}_{3}\left(\mathrm{CH}_{2}\right), \text { 1-Naphthyl } \quad \mathbf{R}^{1}=\mathrm{Me}
\end{aligned}
$$

Scheme 46. One pot three component synthesis of pyrrole derivatives

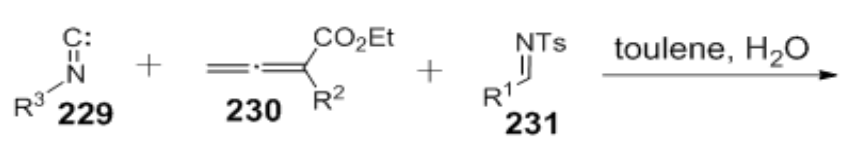

$\mathbf{R}^{1}=\mathrm{C}_{6} \mathrm{H}_{5}, 2-\mathrm{ClC}_{6} \mathrm{H}_{4}, 4-\mathrm{ClC}_{6} \mathrm{H}_{4}, 2-\mathrm{BrC}_{6} \mathrm{H}_{4}, 4-\mathrm{BrC}_{6} \mathrm{H}_{4}, 2-\mathrm{MeC}_{6} \mathrm{H}_{4}$,

$3-\mathrm{MeC}_{6} \mathrm{H}_{4}, 4-\mathrm{MeC}_{6} \mathrm{H}_{4}, 4-\mathrm{MeOC}_{6} \mathrm{H}_{4}, 2,3-\mathrm{Me}, \mathrm{MeC}_{6} \mathrm{H}_{4}, 2,4-\mathrm{Me}$

$\mathrm{MeC}_{6} \mathrm{H}_{4} \mathbf{R}^{2}=3-\mathrm{ClC}_{6} \mathrm{H}_{4}, 4-\mathrm{ClC}_{6} \mathrm{H}_{4}, 3-\mathrm{BrC}_{6} \mathrm{H}_{4}, 4-\mathrm{BrC}_{6} \mathrm{H}_{4}$,

$2-\mathrm{MeC}_{6} \mathrm{H}_{4}, 2-\mathrm{FC}_{6} \mathrm{H}_{4}, 3-\mathrm{MeC}_{6} \mathrm{H}_{4}, 4-\mathrm{MeOC}_{6} \mathrm{H}_{4}$

$\mathbf{R}^{3}=t-\mathrm{Bu}, n$-Pen, i-Pro, $\mathrm{CH}_{2} \mathrm{C}_{6} \mathrm{H}_{4}, \mathrm{p}-\mathrm{C}_{6} \mathrm{H}_{4}$

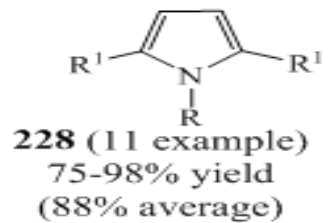

( $88 \%$ average)

Scheme 47. One pot three component synthesis of substituted fused-pyrrolidine

\section{CONCLUSION}

In this review, we have provided an overview of the different multicomponent reactions (MCRs) based strategies for the synthesis of substituted pyrroles, emphasizing on recently reported, eco-friendly protocols. Pyrrole is an important heterocyclic scaffold that has played a significant role in different areas of chemistry, especially medicinal chemistry and drug discovery. Multi-component reactions are versatile and attractive approach in organic synthesis with immense potential for the rapid assembly of complex molecule. More than ninety percent of the MCR protocols published in the last three years are covered in this review. This review particularly covers recent environment friendly protocols for the synthesis of pyrroles which utilize the use of alternate green solvents, green catalysts, catalyst free synthesis or microwave assisted synthesis, the present review will be of immense interest to researchers working on the development of efficient, New, MCR based methodologies for the synthesis of pyrrole compounds.

\section{ACKNOWLEDGEMENT}

The authors are thankful to the R\&D wing of Integral University, Lucknow, India for providing 
support and communication number (IU/R\&D/2017MCN00047) for the manuscript. A. G. A-S. Thanks
Dean, Scientific Research, King Khalid University, Abha Saudi Arabia for administrative support.

\section{REFERENCES}

1. Ghose, A. K.; Vellarkad, N. V.; Wendoloski, J. J. J. Comb. Chem., 1999, 1, 55.

2. Saini, M. S.; Kumar, A.; Dwivedi, J.; Singh. R. Inter. J. Phar. Sci. and Res., 2013, 4, 66.

3. Buchardt, O.; Bove, J. J. Electrochem. Soc., 1977, 124, 235C.

4. Badgujar, D. M.; Talawar, M. B.; Asthana, S. N.; Mahulikar, P. P. J. Hazardous Materials., 2008, 151, 289.

5. Dastan, A.; Kulkarni A.; Torok, B. Green Chem., 2012, 14, 17.

6. Clark, J. H. Green Chem., 1999, 1, 1.

7. Anastas, P. Eghbalia, N. Chem. Soc. Rev., 2010, 39, 301.

8. Constable, D. J. C.; Dunn, P. J.; Hayler, J. D.; Humphrey, G. R.; Leazer, J. L.; Linderman, R. J.; Lorenz, K.; Manley, J.; Pearlman, B. A.; Wells, A.; Zaks, A.; Zhang, T.Y. Green Chem., 2007, 9, 411.

9. Trost, B. M. Acc. Chem. Res., 2002, 35, 695.

10. Gawande, M. B.; Bonifacio, V. D. B.; Luque, R.; Brancoa, P. S.; Varma, R. S. Chem. Soc. Rev., 2013, 42, 5522.

11. Safaei, H. R.; Shekouhy, M.; Rahmanpur S.; Shirinfeshan, A. Green Chem., 2012, 14, 1696.

12. Mallepalli, R.; Yeramanchi, L.; Bantu, R.; Nagarapu, L. Synlett., 2011, 18, 2730.

13. Li, C. J. Chem. Rev., 2005, 105, 3095.

14. Ganguly, N. C.; Roy, S.; Mondal, P.; Saha, R. Tetrahedron Lett., 2012, 53, 7067.

15. Azizian, J.; Karimi, A. R.; Kazemizadeh, Z.; Mohammadi A. A.; Mohammadizadeh, M. R. J. Org. Chem., 2005, 70, 1471.

16. Bhardwaj, V.; Gumber, D.; Abbot, V.; Dhimana, S.; Sharma, P. RSC Adv., 2015, 5, 15233.

17. Huffman, J.W. Curr. Medi. Chem., 1999, 6, 706.

18. Finikova,O. S.; Cheprakov, A. V.; Beletskaya, I. P.; Carroll, P. J.; Vinogradov, S. A. J. Org. Chem., 2004, 69, 522.

19. Akbas, E.; Berber, I.; Sener, A.; Hasanov, B. IL Farmaco., 2005, 60, 23.

20. Tanitame, A.; Oyamada, Y.; Ofugi, K.; Fujimoto, M.; Iwai, N.; Hiyama, Y.; Suzuki K. M.;Yamagishi. J. Med. Chem., 2004, 47, 3693.

21. Mohamed, M. S.; Ali, S. A.; Abdelaziz D. H. A.; Fathallah, S. S. Bio. Med. Res. Inter., 2014, 2014, 1.

22. Melagraki, G.; Afantitis, A.; Igglessi-
Markopoulou, O.; Detsi, A.; Koufaki, M.; Kontogiorgis, C.; Hadjipavlou-Litina, D. J. Eur. J. Med. Chem., 2009, 44, 3020.

23. Farag, A. M.; Ali, K. A.; Mayhoub, A. S.; Abdalla, T. M.; Amr, A. E.; Abdel-Hafez, N.; Abdalla, M. M. Eur. J. Med. Chem., 2010, 45, 5887.

24. Kumar, P. R.; Raju, S. P.; Goud, S.; Sailaja, M.; Sarma, M. R.; Reddy, G. O.; Kumar, M. P.; Reddy, V. K.; Suresh, T.; Hegde, P. Bioorg. Med. Chem., 2004, 12, 1221.

25. El-Gaby, M. S. A.; Gaber, A. M.; Atalla, A. A.; Abd Al-Wahab, K. A. IL Farmaco., 2002, 57, 613.

26. Grehn, L.; Ragnarsson, Ulf. J. Org. Chem., 1981, 46, 3492.

27. Ragno, R.; Coluccia, A.; Regina, G. L.; Martino, G. D.; Piscitelli, F.; Lavecchia, A.; Novellino, E.; Bergamini, A.; Ciaprini, C.; Sinistro, A.; Maga, G.; Crespan, E.; Artico, M.; Silvestri, R. J. Med. Chem., 2006, 49, 3172.

28. Danchev, N.;Bijev, A.;Yaneva, D.; Vladimirova, S.; Nikolova, I. Arch Pharm (Weinheim)., 2006, 339, 670.

29. Gokhan-Kelekci, N.; Yabanoglu, S.; Kupeli, E.; Salgın, U.; Ozgen, O.; Ucar, G.; Yesilada, E.; Kendi, E.; Yesilada, A.; Bilgin, A. A. Bioorg. Med. Chem., 2007, 15, 5775.

30. Knorr, L. Ber. Dtsch. Chem. Ges., 1884, 17, 1635.

31. Roomi, M. W.; MacDonald, S. F. Canadian. J. Chem., 1970, 48, 1689.

32. Bonnaterre, F.; Choussy, B.; Zhu, M. J. Org. Lett., 2006, 8, 4351.

33. Wang, B.; Gu, Y.; Luo, C.; Yang, T.; Yang, L.; Suo. Tetrahedron Lett., 2004, 45, 3417.

34. Estevez, V.; Villacampa, M.; Menendez, J. C. Chem. Soc. Rev., 2014, 43, 4633.

35. Khan, M. M.; Yousuf, R.; Khan, S.; Shafiullah. RSC Adv. 2015, 5, 57883.

36. Wangelin, A. J. von.; Neumann, H.; Gordes, D.; Klaus, S.; Strubing, D.; Beller, M. Chem. Eur. J., 2003, 9, 4286.

37. Domling, A. Current Opinion in Chem. Bio., 2002, 6, 306.

38. Domling, A. Chem. Rev., 2006, 106, 17.

39. Biggs-Houck, J. E.; Younai, A.; Shaw, J. T. Curr. Opin. Chem. Biol., 2010, 14, 371. 
40. Singh, M. S.; Chowdhury, S. RSC Adv., 2012, 2, 4547 .

41. Maclennan, D. H.; Duff, C.; Zorzato, F.; Fuji, J.; Phillips, M. R.; Korneluk, G.; Frodis, W.; Britt, B. A.; Wortont, R. G. Nature., 1990, 343, 559.

42. Lindquist, N.; Fenical, W.; Duyne, G. D. Van.; Clardy, J. J. Org. Chem., 1988, 53, 4570.

43. Rapoport, H.; Holden, K. G. J. Am. Chem. Soc., 1962, 84, 635.

44. Cipres, A.; O’Malley, D. P.; Li, K.; Finlay, D.; Baran, P. S.; Vuori, K. ACS Chem. Biol., 2010, 5, 195.

45. Urban, S.; Butler, M. S.; Capon, R. J. Aust. J. Chem., 1994, 47, 1919.

46. Novozhilov, Y. V.; Dorogov, M. V.; Blumina, M. V.; Smirnov, A. V.; Krasavin, M. Chem. Cent. J., 2015, 9, 7.

47. Morrison, M. D.; Hanthorn, J. J.; Pratt, D. A. Org. Lett., 2009, 11, 1051.

48. Radl, S.; Cerny, J.; Klecan, O.; Stach, J.; Placek, L.; Mandelova, Z. Tetrahedron Lett., 2008, 49, 5316.

49. Mitsui, T.; Kitamura, A.; Kimoto, M.; To, T.; Sato, A.; Hirao, I.; Yokoyama, S. J. Am. Chem. Soc., 2003, 125, 5298.

50. Muller, P.; Polleux, P. Helv. Chim. Acta., 1998, 81,317

51. Papaetis, G. S.; Syrigos, K. N. Bio. Drugs., 2009, 23, 377.

52. Jana, G. H.; Jain, S.; Arora, S. K.; Sinha, N. Bioorg. Med. Chem. Lett., 2005, 15, 3592.

53. Artico, M.; Corelli, F.; Massa, S.; Stefancich, G. J. Het. Chem., 1982, 19, 1493.

54. Gawande, M. B.; Bonifacio, V. D. B.; Luque, R.; Branco, P. S.; Varma, R. S. Chem. Soc. Rev., 2013, 42, 5522.

55. Chanda, A.; Fokin, V. V. Chem. Rev., 2009, 109, 725.

56. Vasuki, G.; Kumaravel, K. Tetrahedron Lett., 2008, 49, 5636.

57. Kumaravel, K.; Vasuki, G. Curr. Org. Chem., 2009, 13, 1820.

58. Kobayashi, S.; Mori, Y.; Nogayama, S.; Manabe, K. Green Chem., 1999, 1, 175.

59. Sheldon, R. A. Green Chem., 2005, 7, 267.

60. Strauss, C. R.; Trainor, R. W. Aust. J. Chem., 1998, 51, 703.

61. Akiya, N. Savage, P. E. Chem. Rev., 2002, 102, 2725.

62. Singh, M.; Saquib, M.; Singh, S. B.; Singh,
S.; Ankit, P.; Fatma, S.; Singh, J. Tetrahedron Lett., 2014, 55, 6175.

63. Jiang, B.; Cao, L. J.; Tu, S. J.; Zheng, W. R.; Yu, H. Z. J. Comb. Chem., 2009, 11, 612.

64. Drop, M.; Bantreil, X.; Grychowska, K.; Mahoro, G. U.; Colacino, E.; Pawlowski, M.; Martinez, J.; Subra, G.; Zajdel, P.; Lamaty, F. Green Chem., 2017, 19, 1647.

65. Martins, P.; Frizzo, P.; Moreira, N.; Zanatta, N.; Bonacorso, G. Chem. Rev., 2008, 108, 2015.

66. Zinovyeva, V. A.; Vorotyntsev, M. A.; Bezverkhyy, I.; Chaumont, D.; Hierso, C. Adv. Func. Mater., 2011, 21, 1064.

67. Veisi, H.; Azadbakht, R.; Ezadifar, M.; Hemmatib, S. J. Het. Chem., 2013, 50, E241.

68. Li, B.; Li, P.; Fang, X.; Li, C.; Sun, J.; Mo, L.; Zhang, Z. Tetrahedron Latt., 2013, 69, 7011.

69. Masoudi, M.; Anary-Abbasinejad, M. 3rd International Conference on Bio. Chem. \& Env. Sci., 2015, 21, 125-136.

70. Reddy, L. M.; Chandrashekar, P. A.; Reddy, R.; Reddy, C. K. Rus. J. Gen. Chem., 2015, 85, 155.

71. Lunagariya, J.; Dhar, A.; Vekariya, R. RSC Adv., 2017, 7, 5412.

72. Zhao, G.; Jiang, T.; Gao, H.; Han, B.; Huang, J.; Sun, D. Green Chem., 2004, 6, 75.

73. Isambert, N.; Duque, M.; Plaquevent, J.; Genisson, Y.; Rodriguez, J.; Constantieux, T. Chem. Soc. Rev., 2011, 40, 1347.

74. Senapak, W.; Saeeng, R.; Jaratjaroonphong, J.; Kasemsuk, T.; Sirion, U. Org. Biomol. Chem., 2016, 14, 1302.

75. Rajaguru, K.; Mariappan, A.; Muthu subramanian, S.; Bhuvanesh, N. Org. Chem. Front., 2017, 4, 124.

76. Shi, L.; Wang, B. Org. Lett., 2016, 18, 2820.

77. Tan, Xue-M.; Lai, Qiao-M.; Yang, Zhi-W.; Long, X.; Zhou, Hai-L.; You, Xiao-L.; Jiang, Xiao-J.; Cui, Hai-L.; Tetrahedron Lett., 2017, 58, 163.

78. Sheikholeslami-Farahani, F. Bulgarian Chem. Commun., 2015, 47, 664.

79. Chen, Xue-B.; Liu, Zhi-C.; Yang, Li-F.; Yan, Sheng-J.; Lin, J. ACS Sustain. Chem. Eng., 2014, 2, 1155.

80. Ramana, D. V.; Vinayak, B.; Dileepkumar, V.; Murty, U. S. N.; Chowhan, L. R.; Rimaz, M. C. M. RSC Adv., 2016, 6, 21789.

81. Viradiya, D. J.; Baria, B. H.; Kakadiya, R.; Kotadiya, V. C.; Shah, A. Int. Lett. Chem, Phy. Astro., 2014, 30, 257. 
82. Wang, H.; Liu, X.; Feng, X.; Huang, Z.; Shi, D. Green Chem., 2013, 15, 3307.

83. Niknam, K.; Khataminejad, M. Org. Chem. Res., 2016, 2, 9.

84. Ambethkar, S.; Padminia, V.; Bhuvanesh, N. New J. Chem., 2016, 40, 4705.

85. Liu, C.; Zhou, L.; Jiang, D.; Gu, Y. Asian J. Org. Chem., 2016, 5, 367.

86. Shi, G.; He, X.; Shang, Y.; Xie, M. RSC Adv., 2016, 6, 10412.

87. Sajadikhah, S. S.; Maghsoodlou, M. T. RSC Adv., 2014, 4, 43454.

88. Kangani, M.; Hazeri, N.; Maghsoodlou, M. T. J. Saudi Chem. Soc., 2017, 21, 160.

89. Kalmode, H. P.; Vadagaonkar, K. S.; Murugan, K.; Prakash, S.; Chaskar, A. C. RSC Adv., 2015, 5, 35166

90. Jagadhane, P. B.; Jadhav, N. C.; Herlekar, O. P.; Telvekar, V. N. Synth. Commun., 2015, 45, 2130.

91. Wang, C.; Jiang, Y-H.; Yan; Guo. C.; Chinese Chem. Lett., 2015, 26, 889.

92. Mishra, R.; Panday, A. K.; Choudhury, L. H.; Pal, J.; Subramanian, R.; Verma, A. Chem. Eur. J., 2017, 2017, 2789.

93. Wei, J.; Liu, L.; Tang, D-N.; Wu, C-P.; Zhao, X-J.; Hao, W-J.; Jiang, B. J. Het. Chem., 2017, 54, 3403

94. Ghandi, M.; Jourablou, A.; Abbasi, A. J. Het. Chem., 2017, 54, 3108.

95. Karamthulla, S.; Jana, A.; Choudhury, L. H. ACS Comb. Sci., 2017, 19, 108.

96. Man, N. N.; Wang, J. Q.; Zhang, L. M.; Wen, L. R.; Li, M. J. Org. Chem., 2017, 82, 5566.

97. Tripoteau, F.; Eberlin, L.; Fox, M. A.; Carboni, B.; Whiting, A. Chem. Commun., 2013, 49, 5414.

98. Dhinakaran, I.; Vediappen, P.; Bhuvanesh, N. ACS Comb. Sci., 2016, 18, 236.

99. Gabrielli, S.; Ciabattoni, L.; Sampaolesi, S.; Ballini, R.; Palmieri, A. RSC Adv., 2016, 6, 44341.

100. Leonardi, M.; Villacampa, M.; Menendez, J. C. J. Org. Chem., 2017, 82, 2570.

101. Li, J.; Liu, Y.; Li, C.; Jia, X. Chem. Eur. J., 2011, 17, 7409 .

102. Tang, Z.; Liu, Z.; An, Y.; Jiang, R.; Zhang, X.; Li, C.; Jia, X.; Li, J. J. Org. Chem., 2016, 81, 9158.

103. Manjappa, K. B.; Peng, Y. T.; Jhang, W. F.; Yang, D. Y. Tetrahedron, 2016, 72, 853.

104. Tian, Y.; Tian, L.; He, X.; Li, C.; Jia, X.; Li, J.
Org. Lett., 2015, 17, 4874.

105. Tian, Y.; Tian, L.; Li, C.; Jia, X.; Li, J. Org. Lett., 2016, 18, 840.

106. Gein, V. L.; Yankin, A. N.; Nosova, N. V.; Dmitriev, M. V.; Slepukhin, P. A. Tetrahedron Lett., 2016, 57, 2441.

107. Wu, J.; Chen, X.; Xie, Y.; Guo, Y.; Zhang, Q.; Deng, G. J. J. Org. Chem., 2017, 82, 5743.

108. Fleige, M.; Glorius, F. Chem. A Eur. J., 2017, 23, 10773.

109. Cores, A.; Estevez, V.; Villacampa, M.; Menendez, J. C. RSC Adv., 2016, 6, 39433.

110. Banerjee, D.; Karmakar, R.; Kayal, U.; Maiti, G. Synth. Commun., 2017, 47, 1006.

111. Deshmukh, S. M.; Hiwarale, D. P. Der Pharma Chemica., 2017, 9, 109.

112. Asghari, S.; Qandalee, M.; Behboodi, V.; Gorji, A. N.; Pasha, G. F. Chin. Chem. Lett., 2016, 27, 361.

113. Zheng, Y.;Wang, Y.; Zhou, Z. Chem. Commun., 2015, 51, 16652.

114. Shahvelayati, A. S.; Sabbaghan, M.; Banihashem, S. Int. J. Bio-Inorg. Hybr. Nanomater., 2015, 4, 73.

115. Raju, A. R.; Reddy, R. V.; Rao, V. M.; Naresh, V. V.; Rao, A. V. Tetrahedron Lett., 2016, 57, 2838.

116. Mehrabi, H.; Anary-Abbasinejad, M.; Mirhashemi, F. Tetrahedron Lett., 2014, 55, 4310.

117. Mariappan, A.; Rajaguru, K.; Muthusubramanian, S.; Bhuvanesh, N. Synth Commun., 2016, 46, 805.

118. Zhao, D.; Zhu, Y.; Guo, S.; Chen, W.; Zhang, G.; Yu, Y. Tetrahedron., 2017, 73, 2872.

119. Davis-Gilbert, Z. W.; Hue, J. R.; Tonks, I. A. Nature Chem., 2016, 8, 63.

120. Saleh, N. Voituriez, A. J. J. Org. Chem., 2016, 81, 4371.

121. Modugu, N. R.; Pittala, P. K. Cogent Chem., 2017, 3, 1.

122. Panther, J.; Muller, T. J. J. Synthesis., 2016, 48, 974.

123. Rimaz, M.; Mousavi, H.; Nikpey, L.; Khalili, B. Research Chem Intermed., 2017, 43, 3925.

124. Daw, P.; Chakraborty, S.; Garg, J. A.; BenDavid, Y.; Milstein, D. Angew. Chem. Int. Ed., 2016, 55, 14373.

125. Karami, B.; Khodabakhshi, S.; Jamshidi, M. J. Chin. Chem. Soc., 2013, 60, 1103.

126. Jiang, H.; Tian, Y.; Tian, L.; Li, J. RSC Adv., 2017, 7, 32300. 